\title{
How Much Does “Backing Aloft” Actually Impact a Supercell?
}

\author{
MATTHEW D. PARKER \\ North Carolina State University, Raleigh, North Carolina
}

(Manuscript received 15 May 2017, in final form 8 September 2017)

\begin{abstract}
Among forecasters and storm chasers, there is a common perception that hodographs with counterclockwise curvature or kinking in the midlevels (sometimes called backing aloft or veer-back-veer profiles) are unfavorable for long-lived supercells and tornadoes. This study reviews and then evaluates several possible explanations for the purported negative effect of backing aloft. As a controlled hypothesis test, simulated supercells are initiated within a range of idealized wind profiles, many of which include representative counterclockwise kinks or bends in their hodographs. In these experiments, the short-term, direct impacts of backing aloft upon supercell maintenance are generally small. Backing aloft does modify the component of vertical accelerations linked to updraft-shear interactions, but these changes generally occur well above the level of free convection (LFC), and they are generally offset by substantial upward accelerations attributable to other processes (e.g., within-storm rotation and positive buoyancy). In these simulations, the longevity of isolated supercells seems to be most directly hindered in environments with very low storm-relative helicity (SRH) or else (for a line of supercells) substantial along-line flow in the upper troposphere. Although these two disrupting properties can accompany backing aloft, they are neither universally nor exclusively associated with it. From the perspective of storm dynamics, it seems advisable to focus on SRH and along-line flow in the environment, rather than the presence (or absence) of backing aloft in the wind profile.
\end{abstract}

\section{Introduction}

A majority of long-lived supercells in the United States occur in wind profiles where the vertical wind shear vector veers with height (e.g., Markowski et al. 2003). On a hodograph diagram, such profiles are often referred to as "clockwise (CW) curving." When forecasters and storm chasers refer to "backing aloft" or "veer-back-veer" profiles, they customarily mean a hodograph with counterclockwise $(\mathrm{CCW})$ curvature or kinking somewhere in the middle troposphere (see examples in Fig. 1). Such CCW inflections mean that the vertical wind shear vector backs with height in that layer; this specific condition will be casually called backing aloft in the present paper. In practice, these hodographs often have what might be dubbed "backward S" shapes (e.g., Figs. 1a,c,d). Forecast discussions from major operational centers and storm chasers generally imply that

Supplemental information related to this paper is available at the Journals Online website: https://doi.org/10.1175/ WAF-D-17-0064.s1.

Corresponding author: Matthew D. Parker, mdparker@ncsu.edu these kinds of vertical wind profiles are unfavorable for long-lived discrete supercell storms, despite having deep-layer vertical wind shear values that would otherwise support supercellular convection.

This seems to be a case in which there is generally accepted anecdotal wisdom within the field, despite the fact that there have been essentially no peer-reviewed studies $^{1}$ on the topic. The author has anonymously recorded numerous claims from storm forecasters and scientists over the years who argue (for example) that storms often rapidly transition into more linear convection in such environments. It has also been pointed out that the nontornadic supercell composite wind profile from the second Verification of the Origins of Rotation in Tornadoes Experiment (VORTEX2) shows some evidence of backing aloft, whereas the tornadic

\footnotetext{
${ }^{1}$ Warren et al. (2017) did include a simulation with backing aloft in their sensitivity study of how upper-level shear impacts supercell simulations. However, they applied the backing above $6 \mathrm{~km}$ AGL, which would be quite high within the context of the sorts of hodographs that motivate the present study (e.g., Fig. 1). Mulholland et al. (2015) also gave a recent conference presentation examining a case study with backing aloft.
} 

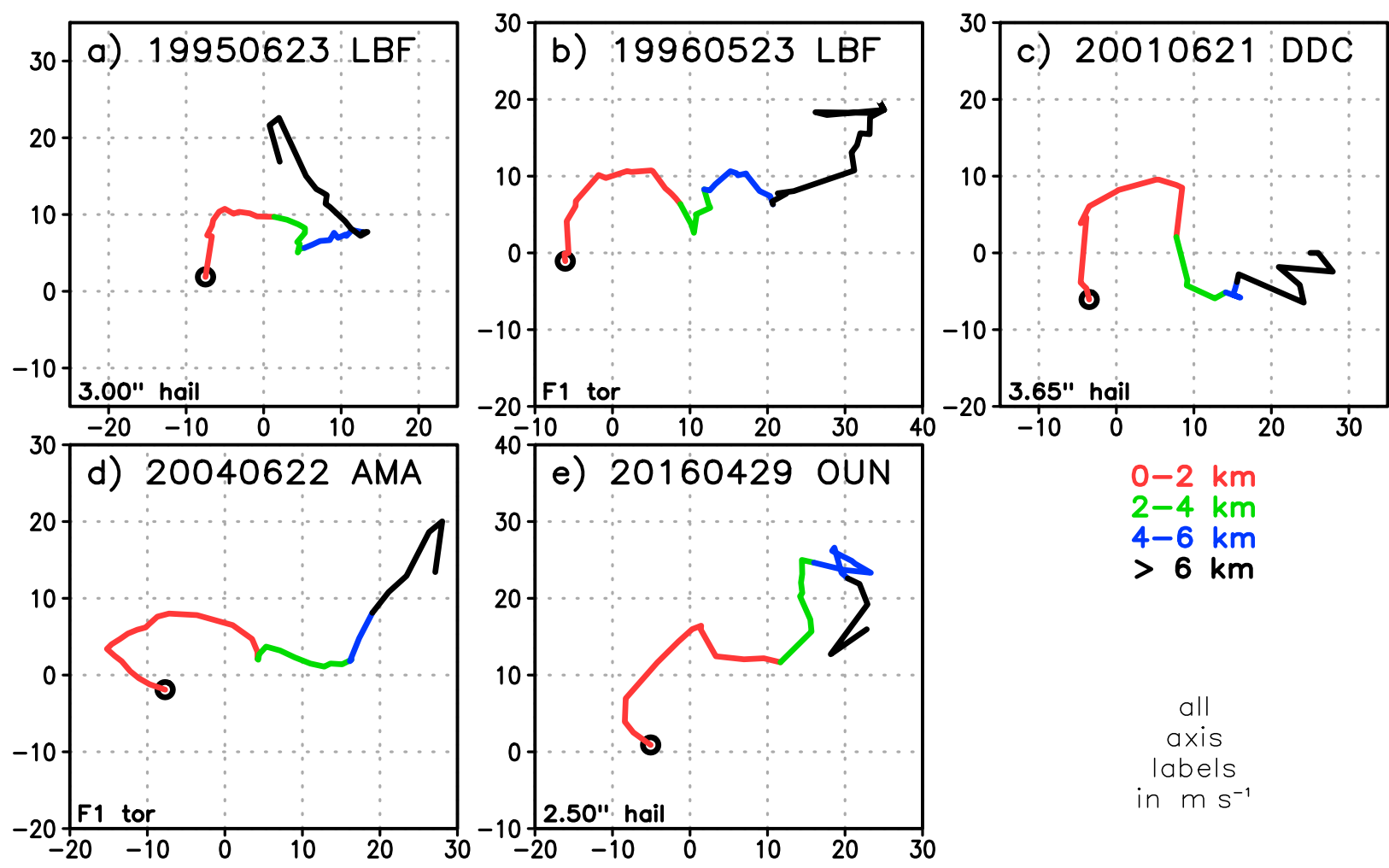

FIG. 1. Environmental hodographs possessing either a kink or a layer of CCW curvature aloft, for a variety of severe weather cases. Cases are identified at the top of each panel by their date and three-letter station identifier. At the bottom left of each panel, the most significant nearby storm report is indicated (either a tornado's Fujita-scale rating or the maximum hail size measured nearby). Height levels of layers on the hodographs are indicated with colors, as shown.

composite does not (Parker 2014, his Fig. 12). Notably, even the nontornadic storms in the Parker (2014) study were still intense supercells, and the simulation performed by Coffer and Parker (2017) using the nontornadic composite VORTEX2 environment also produced a long-lived (but not tornadic) supercell.

Given the apparent lack of published work on the topic, it is difficult to formulate a compelling literature review to motivate this study. Therefore, it proves useful to discuss the possible meteorological reasoning for why supercells could be weaker or less well organized in environments with backing aloft. In the author's experience, the perceived unfavorability of backing aloft is typically attributed to one or more of the following. 1) CCW turning of the shear vector with height disrupts the dynamical vertical perturbation pressure gradient accelerations in typical right-moving supercells. 2) Backed winds aloft cause the supercell storm motion to fall quite close to the hodograph, meaning that there is a much smaller amount of storm-relative helicity (which represents the influx of streamwise horizontal vorticity that is available to produce updraft rotation). 3) Backing aloft modifies the middle- to upper-level storm-relative flow, which could modify the precipitation and outflow structures of storms and favor subsequent interactions or mergers. Before introducing the experimental design, we briefly consider the rationale for these three hypotheses (and also the null hypothesis), in turn.

Notably, the aforementioned mechanisms would operate predominantly on the storm scale, making them amenable to testing with an idealized cloud model. Alternatively, it is also possible that some aspect of the larger-scale environment that accompanies the backing of winds/shear vectors with height could indirectly hinder the production of discrete supercells. Unfortunately, this kind of synoptic-convective-scale interaction is not readily testable in the present modeling framework (section 2). So, for this initial study, we focus on the purported storm-scale impacts.

\section{a. Possible impacts upon updraft-shear interactions}

Rotunno and Klemp (1982) laid out a framework for understanding dynamical vertical accelerations in supercell thunderstorms. They sought to explain the wellknown fact that the rightward-moving member of a splitting supercell storm predominates in environments in which the vertical wind shear vector veers with height (i.e., CW-turning hodographs). The linear part of the 
diagnostic equation for dynamic pressure perturbations (for more information, see section $2 \mathrm{c}$ ) reveals that in environments with $\mathrm{CW}$-turning hodographs, the vertical arrangement of pressure perturbations favors enhanced upward accelerations on an updraft's right flank (with respect to the deep-layer vertical shear); the vertical accelerations are correspondingly suppressed on the updraft's left flank. As a corollary, in a CCW-turning hodograph (one where the shear vector backs with height), upward accelerations are enhanced on an updraft's left flank but suppressed on its right flank.

In light of this dynamical influence, it stands to reason that a layer of backing aloft (i.e., a part of the hodograph that turns $\mathrm{CCW}$, not $\mathrm{CW}$ ) would interrupt the usually favorable upward perturbation pressure gradient accelerations for a right-moving supercell. This might lead to storms that are less steady and weaker (and perhaps even to dissipation of the storm). The challenge in applying this conceptual model is that in most of the hodograph spectrum, the nonlinear dynamical vertical accelerations (associated with flow perturbations apart from the basic updraft-shear interactions) are usually at least as large as the linear contributions (e.g., Weisman and Rotunno 2000). The present study quantifies and compares these effects across a range of hodographs both with and without a layer of backing aloft. The next subsection further discusses the nonlinear dynamical contributions just mentioned.

\section{b. Possible impacts upon updraft rotation}

It has long been known that the tilting of streamwise vorticity (vorticity that is parallel to the storm-relative winds) leads to vertical rotation that is correlated with upward motion in supercell storms (Davies-Jones 1984). Storm-relative helicity (SRH) is the vertically integrated flux of streamwise vorticity toward a storm (by the storm-relative winds). Modeling studies and operational climatologies have shown that SRH is in turn well correlated to the intensity and longevity of rotation in rightmoving supercells (e.g., Rasmussen and Blanchard 1998; Thompson et al. 2003, 2007). In part, this sensitivity of storm strength to SRH can be understood in terms of the nonlinear dynamic pressure minima that develop in zones of strong rotation [Rotunno and Klemp (1982); Weisman and Rotunno (2000), etc.; see also section 2c]; larger SRH favors a stronger mesocyclone, larger pressure falls, and thus a greater upward-directed dynamic pressure gradient acceleration in the column beneath the mesocyclone (e.g., Markowski and Richardson 2014; Coffer and Parker 2015, 2017).

The motion of a supercell thunderstorm is the sum of advection by the mean wind in the cloud-bearing layer and propagation that is due to the effects of the linear and nonlinear dynamic accelerations as well as any forcing by moving surface outflows. SRH can be depicted graphically as twice the signed area swept out in the $\mathrm{CW}$ direction between the storm-relative wind vectors at two levels in the hodograph (often between the surface and $3 \mathrm{~km}$ AGL in operations). All other things being equal, the farther the storm motion vector falls from the hodograph, the larger the storm-relative winds and SRH will be (i.e., the greater the $\mathrm{CW}$ area swept out along the hodograph). Backing aloft in the vertical wind profile may shift the mean cloud-layer wind to the left, causing a right-moving storm's motion to fall closer to the hodograph (and thus diminishing the SRH). Thus, the hypothesized chain of causation is that, despite there being no change in the lower-tropospheric winds, backing aloft leads to right-moving supercells whose motion falls closer to the environmental hodograph, thereby decreasing SRH and thus weakening the updraft's rotation and its subsequent nonlinear dynamic vertical accelerations.

\section{c. Possible impacts upon precipitation distribution and subsequent storm interactions}

It is fairly well established that the storm-relative winds at various altitudes are responsible for the general arrangement of hydrometeors in a supercell (e.g., Browning 1964; Lemon and Doswell 1979; Brooks et al. 1994; Rasmussen and Straka 1998; Kumjian and Ryzhkov 2009; Dawson et al. 2015). Thus, it seems reasonable that backing aloft might impact a supercell by changing either the magnitude or direction of hydrometeor advection within the storm. Backing aloft might be favorable for longer-lived supercells to the extent that it causes precipitation to be displaced increasingly CCW from the storm's inflow sector. In contrast, it might be unfavorable for longer-lived supercells if the storm motion falls too close to the environmental hodograph (as in the previous subsection); this would imply weak storm-relative winds, which may be associated with very heavy precipitation adjacent to the updraft (e.g., Brooks et al. 1994; Rasmussen and Straka 1998). In turn, precipitation location, intensity, and size distribution can also impact the strength of the resulting low-level outflows. Proper evaluation of these concepts would be very computationally expensive (involving either a very sophisticated microphysical parameterization or an ensemble using several different microphysical parameterizations). Such approaches were not possible for the present study, but where appropriate we will simply describe the simulated precipitation and outflow structures as they relate to the environmental hodograph.

Beyond the impacts to the precipitation structure of an isolated storm, the wind profile may also affect 
interactions between the outflows and hydrometeor fields of adjacent storms. Although a line of discrete supercells may initially develop given a linear forcing mechanism within favorable vertical wind shear, subsequent mergers and upscale growth likely depend upon the orientation of the hodograph relative to the linear forcing (e.g., Bluestein and Weisman 2000). Parker (2007a) and French and Parker (2008) found that enhanced along-line flow aloft was associated with the transport of hydrometeors and "seeding" of neighboring cells farther downwind along the line, which appears to enhance precipitation rates and the production of cold surface outflows. Dial et al. (2010) found that discrete cells were most likely to persist in environments with strong across-boundary flow, which they attributed both to the propensity of the cells to move off of the triggering boundary (thus escaping the strong linear lifting) as well as avoidance of the aforementioned seeding and outflow merger effects [see also Fig. 9.2 and related discussion by Markowski and Richardson (2010)]. In contrast, Dial et al. (2010) found that greater along-boundary flow was associated with more frequent transitions to squall line-like structures.

Thus, another possible ramification of backing aloft is that the resulting middle- and upper-tropospheric flow may be more directly oriented along a mesoscale or synoptic boundary responsible for initiating storms (e.g., a cold front or dryline). If this hypothesis is correct, then one would expect that on occasions where a single isolated supercell is initiated, wind profiles with CCW curvature aloft would have a less deleterious effect than on those occasions where a number of supercells are initiated in close proximity to one another in a line. This between-storm interactions hypothesis is not mutually exclusive of the within-storm dynamical hypotheses outlined in sections $1 \mathrm{a}$ and $1 \mathrm{~b}$; the possibility also exists that multiple mechanisms hinder supercell maintenance in tandem. The present study compares simulations with a single initiated storm versus a line of three storms in order to separate these effects.

\section{d. Evidence for the null hypothesis}

It is also certainly possible that there are only weak physical linkages between backing aloft in the wind profile and the relative likelihood of long-lived discrete supercells. It seems that supercells and tornadoes do at least occasionally occur in such environments: "[Looking at] hodograph plots from big tornado outbreaks... the most common eye-catching feature was... a layer of backing aloft" (E. Rasmussen 2016, personal communication). In addition to the examples shown here in Fig. 1, Nowotarski and Jensen (2013) found that several nodes of their self-organizing hodograph maps (their nodes 5 and 8 , and to a lesser extent nodes $3,4,6$, and 9) included at least weak backing aloft yet were commonly associated with supercells (many of them tornadic); their exemplar cases for two significant tornado outbreaks (see Fig. 6 in Nowotarski and Jensen 2013) had very pronounced CCW hodograph kinks as well. It is also worth noting that several of the best-known supercell tornadogenesis studies were initialized with hodographs having a layer of CCW turning with height; examples include the Wicker and Wilhelmson (1995) profile (which was based on a combination of three different tornadic cases) as well as the Orf et al. (2017) profile (which was based on the El Reno, Oklahoma, EF5 tornado from 2011). In short, the null hypothesis (that backing aloft is not a hindrance to persistent discrete supercells) cannot easily be dismissed, and must also be addressed by our experiments. Toward this end, the sensitivity tests include a range of different hodograph shapes that are each inspired by observed profiles from real cases (see section $2 b$ ).

The experimental design is described in section 2 . Results from simulations initiating a single storm are detailed in section 3. Building upon the isolated storm simulations, section 4 describes results from experiments in which a line of storms is initiated. Section 5 briefly considers some longer-term patterns of behavior in a subset of the simulations. The paper concludes with a summary in section 6 .

\section{Methods}

To isolate the possible roles of backing aloft upon the internal processes of supercells that form in such environments, we analyze a suite of numerical sensitivity tests. The model configuration and basic analysis techniques are explained in this section.

\section{a. Numerical model}

This study utilized idealized simulations from the Bryan cloud model (CM1; Bryan and Fritsch 2002; Bryan and Morrison 2012), release 17. For all runs reported here, the horizontal grid spacing was uniformly $250 \mathrm{~m}$. The model top was $16.5 \mathrm{~km}$ with vertical grid spacing stretching from $100 \mathrm{~m}$ at the model bottom to $250 \mathrm{~m}$ aloft. The horizontal domain spanned $250 \mathrm{~km}$ in the east-west direction; the north-south extent was $150 \mathrm{~km}$ for runs in which a single storm was initiated and expanded to $210 \mathrm{~km}$ for runs in which three storms were initiated (more details on this below).

All four lateral boundaries of the domain used the open radiative boundary condition. The upper and lower boundaries were flat, rigid, free-slip plates, with Rayleigh damping applied in the top $2.5 \mathrm{~km}$ of the 
domain to absorb vertically propagating perturbations near the model lid. Cloud and precipitation microphysics were parameterized using the National Severe Storms Laboratory's bulk two-moment scheme that includes both graupel and hail with variable densities (Ziegler 1985; Mansell et al. 2010). Subgrid-scale turbulence was parameterized via the 1.5-order closure based on predicted turbulent kinetic energy (e.g., Deardorff 1980). For simplicity, no surface fluxes, no Coriolis accelerations, and no radiative processes were included.

For the first set of simulations, initial convective development was triggered by a warm bubble with a cosine-shaped potential temperature perturbation having a peak amplitude of $5 \mathrm{~K}$, a horizontal radius of $5 \mathrm{~km}$, and a vertical radius of $1.4 \mathrm{~km}$ (centered at $1.4 \mathrm{~km}$ AGL); trial and error revealed that this magnitude and geometry was sufficient to trigger deep convection in all experiments. To emulate a line of developing storms in the second set of simulations, a north-south array of three warm bubbles was applied; the bubble strengths and shapes were equivalent to the single-bubble runs, and had a $y$ spacing of $30 \mathrm{~km}$ (this is the distance from bubble center to bubble center). The $30-\mathrm{km}$ spacing is the same as what Bluestein and Weisman (2000) used to study supercell interactions; trial and error revealed that this spacing enabled storm interactions to occur within the simulated time frame (but not immediately after starting the model). In either case, the single bubble (or the middle of the three bubbles) was centered in $x$ and $y$ within the model domain, and the model domain was subsequently translated to keep the simulated storms nearly stationary.

Simulations were carried out for $2 \mathrm{~h}$ under the assumption that the purported environmental impacts upon storm intensity and organization should become obvious once sufficient time has passed for supercell structures to develop and mature. For example, many modern supercell simulations produce tornadoes in less than 2 h of run time (e.g., Coffer and Parker 2017; Orf et al. 2017). If discrete supercells persist through at least $2 \mathrm{~h}$ in an environment with backing aloft, then it would seem that any direct impacts of the wind profile upon the storm are quite small.

\section{b. Initial profiles and modifications}

The initial thermodynamic sounding is the same as the one used by Coffer and Parker (2017) (a skew $T-\log p$ depiction is available in the supplemental material available online; see Fig. S1). This sounding is taken from the near-inflow location of the composite environmental analysis of tornadic supercells from VORTEX2 (Parker 2014). The thermodynamic profiles are not changed in these experiments; only the wind profile is.

Based upon a sampling of wind profiles such as those depicted in Fig. 1, a suite of simple analytical wind profiles was designed for experimentation. As a baseline, we include the classical "half circle" and "quarter turn" hodographs (profiles A and B in Fig. 2), which are simple representations of common supercell environments ${ }^{2}$ and have been used in countless numerical studies of supercells. Variants from these hodographs are constructed with differing amounts of CCW curvature or kinking aloft (Fig. 2); the variants are designed so that they have very similar 0-6-km shear vector magnitudes [well above the $20 \mathrm{~m} \mathrm{~s}^{-1}$ thought to be necessary for supercells; e.g., Rasmussen and Blanchard (1998)] and, with the exception of profile $A$, they have an identical $\mathrm{CW}$-curving segment in the lowest $2 \mathrm{~km}$ AGL. Hodographs B, C, and D have identical starting and ending points within a ground-relative framework, ${ }^{3}$ as do the hodographs A, G, and $\mathrm{H}$. Meanwhile, the progression among hodographs $\mathrm{D}, \mathrm{E}$, and $\mathrm{F}$ involves an increasingly shallow layer of CW curvature beneath the abrupt transition to linear shear aloft. These assorted combinations notably possess different SRHs despite comparable deep-layer vertical wind shear (0-3-km SRH and $0-6-\mathrm{km}$ shear vector magnitude are plotted in each panel of Fig. 2).

For the single-storm runs, evolution is insensitive to the orientation of the hodograph (because there is no surface drag, the environment is horizontally homogeneous, and the domain is translated to keep the storm centered). For the three-storm runs, however, the orientation of the wind profile to the line of developing storms may be quite relevant, as reviewed in section $1 \mathrm{c}$. Therefore, for the three-storm runs, we analyze simulations with the hodographs as shown in Fig. 2, and also using these same hodograph shapes but with the entire hodograph rotated $45^{\circ}$ to the left (i.e., turned CCW about the origin). These rotated profiles have the same structure and bulk parameters (SRH and deep layer shear) as their nonrotated counterparts in Fig. 2, but the component of (southerly) along-line flow is enhanced through most of the depth of the wind profile.

\footnotetext{
${ }^{2}$ For example, the quarter-turn structure resembles the mean hodographs of the Markowski et al. (2003) supercell climatology, and the half-circle structure resembles the hodograph of the famous Del City, OK, tornado (Klemp et al. 1981).

${ }^{3}$ The velocities represented in Fig. 2 are storm relative. Because of differing storm motions among the simulations, the starting and ending points of the storm-relative hodographs do vary slightly among profiles $\mathrm{B} / \mathrm{C} / \mathrm{D}$ and $\mathrm{A} / \mathrm{G} / \mathrm{H}$. Even so, the vector wind difference between the starting and ending points is identical.
} 

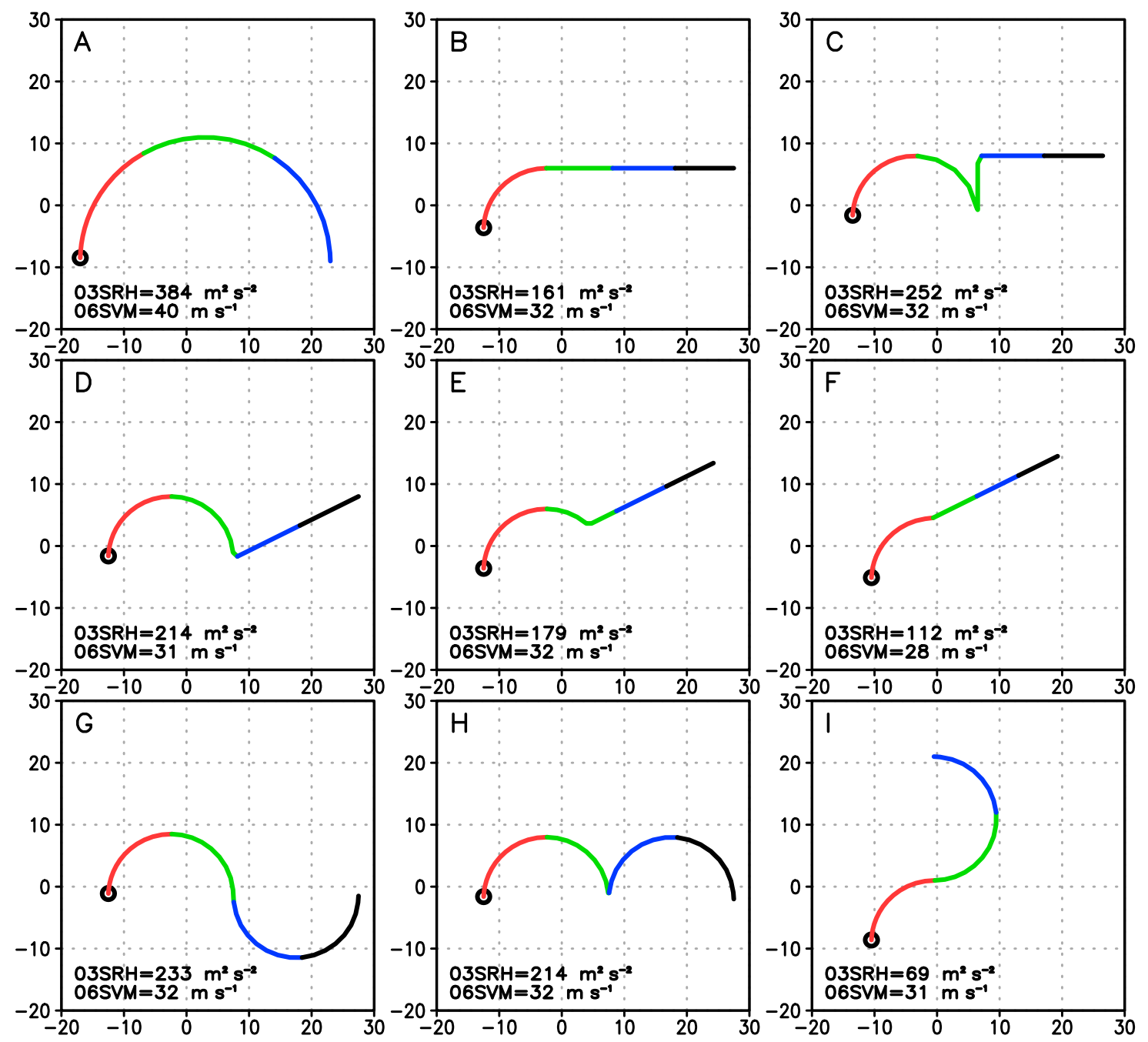

all

axis

labels

in $\mathrm{m} \mathrm{s}^{-1}$

FIG. 2. Environmental hodographs (labeled from A to I) used for initial conditions in the primary sensitivity test simulations. All wind vectors on these hodographs are plotted using the model domain's motion as the origin (effectively making these storm-relative hodographs). The 0-3-km SRH (03SRH) and 0-6-km bulk shear vector magnitude (06SVM) for these hodographs are reported in the bottom left of each panel. Height levels of layers in the hodographs are indicated with colors, as shown.

\section{c. Analysis of pressure perturbations}

To address the dynamical hypotheses presented in sections $1 \mathrm{a}$ and $1 \mathrm{~b}$, we assess the components of the perturbation pressure field $p^{\prime}$. The total $p^{\prime}$ field is taken from the original CM1 output. Following Wilhelmson and Ogura (1972) and Rotunno and Klemp (1982), the buoyant and dynamic components of the pressure perturbation satisfy $p^{\prime}=p_{B}^{\prime}+p_{D}^{\prime}$, and can be diagnosed (for the anelastic Boussinesq system) using

$$
\nabla^{2} p_{B}^{\prime}=\frac{\partial}{\partial z}\left(\rho_{o} B\right)
$$

where $B \equiv-g\left(\rho^{\prime} / \rho_{o}+q_{h}\right)$ is the buoyancy (including fluctuations in density $\rho$, as well as loading associated with the hydrometeor mixing ratio $q_{h}$ ), and

$$
\begin{aligned}
\nabla^{2} p_{D}^{\prime}= & -\rho_{o} \underbrace{\left[\left(\frac{\partial u}{\partial x}\right)^{2}+\left(\frac{\partial v}{\partial y}\right)^{2}+\left(\frac{\partial w}{\partial z}\right)^{2}-w^{2} \frac{\partial^{2}}{\partial z^{2}}\left(\ln \rho_{o}\right)\right]}_{\text {extension terms }} \\
& -2 \rho_{o} \underbrace{\left(\frac{\partial v}{\partial x} \frac{\partial u}{\partial y}+\frac{\partial u}{\partial z} \frac{\partial w}{\partial x}+\frac{\partial v}{\partial z} \frac{\partial w}{\partial y}\right)}_{\text {shear terms }},
\end{aligned}
$$

where $[u, v, w]$ are the Cartesian $[x, y, z]$ velocity components. By separating the velocities into mean and perturbation parts, one can further isolate the linear component of (2), which represents the effects of interactions between the updraft (note that there is no base-state $w_{o}$, so $w=w^{\prime}$ ) and the ambient vertical wind 
shear (associated with the base-state horizontal wind components $u_{o}$ and $v_{o}$ ):

$$
\nabla^{2} p_{D L}^{\prime}=-2 \rho_{o}\left(\frac{d u_{o}}{d z} \frac{\partial w}{\partial x}+\frac{d v_{o}}{d z} \frac{\partial w}{\partial y}\right) .
$$

All remaining nonlinear terms in (2), corresponding to local rotation and deformation in the perturbation wind field, are encapsulated by $p_{D \mathrm{NL}}^{\prime}=p_{D}^{\prime}-p_{D L}^{\prime}$.

We retrieve these $p^{\prime}$ components iteratively using the same Gauss-Seidel relaxation solver as Parker and Johnson (2004a,b), Parker (2007b, 2010), Davenport and Parker (2015), and Coffer and Parker (2015, 2017). Once all pressure perturbation components are retrieved on all grid points, we then calculate the components of the vertical acceleration using

$$
\underbrace{\frac{D w}{D t}}_{\mathrm{ACC}}=\underbrace{B-\frac{1}{\rho_{o}} \frac{\partial p_{B}^{\prime}}{\partial z}}_{\mathrm{ACCB}}-\underbrace{\frac{1}{\rho_{o} \frac{\partial p_{D L}^{\prime}}{\partial z}}-\underbrace{\frac{1}{\rho_{o}} \frac{\partial p_{D N L}^{\prime}}{\partial z}}_{\mathrm{ACCDL}}}_{\mathrm{ACCD}} .
$$

In the remainder of this article, the components of acceleration in (4) are referred to by the names beneath the braces. ACCB is the total buoyant acceleration, which includes both the buoyant vertical perturbation pressure gradient acceleration as well as the vertical acceleration due to buoyancy itself. Thus, ACCB can be equated to the concept of "effective buoyancy" [i.e., buoyancy in excess of what is balanced by the static pressure field, irrespective of an arbitrary base state, e.g., Davies-Jones (2003); Doswell and Markowski (2004); Jeevanjee and Romps (2015); Peters (2016)]. ACCD is the total dynamical acceleration, which includes both the linear (ACCDL) and nonlinear (ACCDNL) parts of the dynamical perturbation pressure gradient acceleration. As discussed by Weisman and Rotunno (2000), in supercells ACCDL is commonly associated with updraft-shear interactions (sometimes also called the updraft-in-shear effect), and ACCDNL is commonly associated with vertical changes in the pressure falls that are linked to vertical vorticity (what might be called the updraft rotation effect) as well as pressure rises in localized zones of deformation (generally of lesser consequence in the midlevels of supercell updrafts).

\section{Results from single-storm simulations}

First, we consider the experiments in which a single storm is initiated using one warm bubble. Eight of the nine simulations produce discrete supercells that persist through $2 \mathrm{~h}$ (Fig. 3; an animated version of this is available in Fig. S2). The lone exception is hodograph I. Given the low-level $\mathrm{CW}$ curvature of the hodographs and positive SRH, right-moving supercells predominate in these simulations (A-H in Fig. 3), although a somewhat persistent left mover also occurs in simulation $\mathrm{F}$, as might be anticipated for a nearly straight hodograph. The eight long-lived storms have typical reflectivity structures, with peak values of vertical velocity $w \geq$ $45 \mathrm{~m} \mathrm{~s}^{-1}$ and $3-\mathrm{km}$ vertical vorticity $\zeta \geq 0.05 \mathrm{~s}^{-1}$.

The orientation of the upper-level flow clearly affects the position and orientation of the forward-flank precipitation in the simulated storms. Much as surmised by Rasmussen and Straka (1998), one apparent impact of backing aloft is that the down-shear zone of supercell precipitation is shifted to the left (counterclockwise; e.g., C, D, E, F, H in Fig. 3), giving these storms a somewhat more classical appearance than, for example, the structure simulated in the half-circle hodograph (A in Fig. 3). Overall, there is no indication that the inclusion of backing aloft uniformly makes the supercells' updrafts or mesocyclones weaker, nor their precipitation structures less organized. The obvious counterexample is the storm in hodograph I, which is extremely weak and disorganized; that simulation will be discussed separately in section 3b. However, among the eight long-lived supercells, the updraft is actually weakest in the half-circle hodograph A (which contains no backing) and the nearly straight hodograph $\mathrm{F}$ (which has very little).

Despite the modest differences in peak updraft intensity (as plotted for each run in Fig. 3), the simulations (except for profile I) are remarkably similar in terms of their lower- and middle-tropospheric vertical velocities (Fig. 4); for the "healthy" supercells (profiles A-H), $w$ at $4.5 \mathrm{~km}$ AGL (i.e., just above the height where the "kink" or onset of backing typically occurs) varies only narrowly from 29.1 to $32.7 \mathrm{~m} \mathrm{~s}^{-1}$. In contrast, the updrafts become rather different from one another above $4.5 \mathrm{~km}$ AGL (Fig. 4). Profiles A and F (both of which have little or no backing) peak at less than $40 \mathrm{~m} \mathrm{~s}^{-1}$, with almost no vertical change above $6 \mathrm{~km}$ AGL. In contrast, profiles $\mathrm{C}, \mathrm{E}$, and $\mathrm{G}$ (all of which have backing/kinking aloft) produce $w$ approaching $60 \mathrm{~m} \mathrm{~s}^{-1}$ in the upper troposphere. These simulated differences in uppertropospheric ascent might have indirect impacts associated with different pathways for precipitation formation and fallout, but the lower-tropospheric processes that sustain the supercells' updrafts are clearly not directly hindered by the inclusion of backing aloft. Although accelerations can partly be inferred from the vertical gradients of $w$ in Fig. 4, the next section considers the components of vertical acceleration more precisely.

\section{a. Updraft accelerations in the healthy supercells}

Although the end result is a long-lived discrete ("healthy") supercell in eight of the nine hodographs, it 

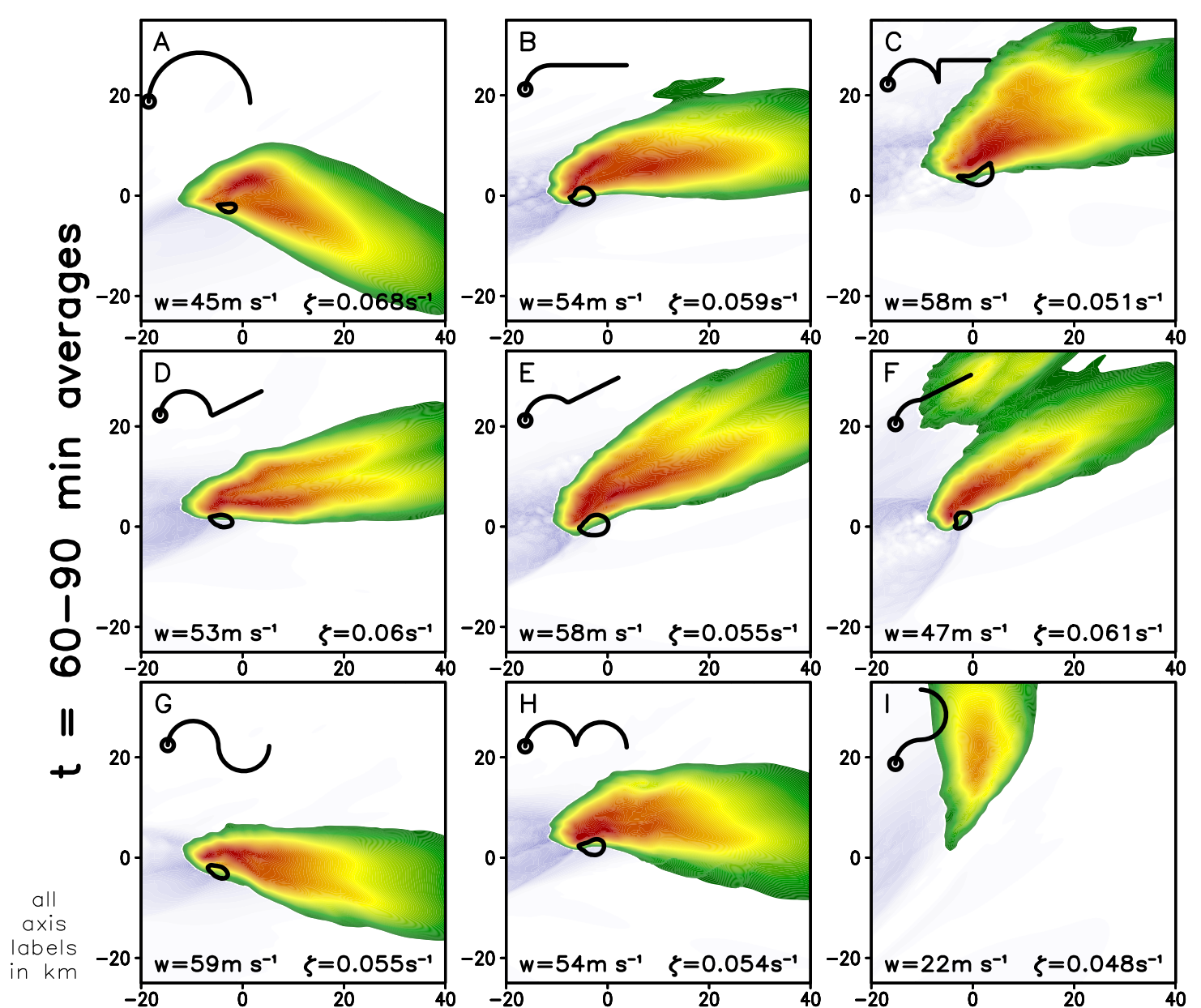

refl. (dBZ)
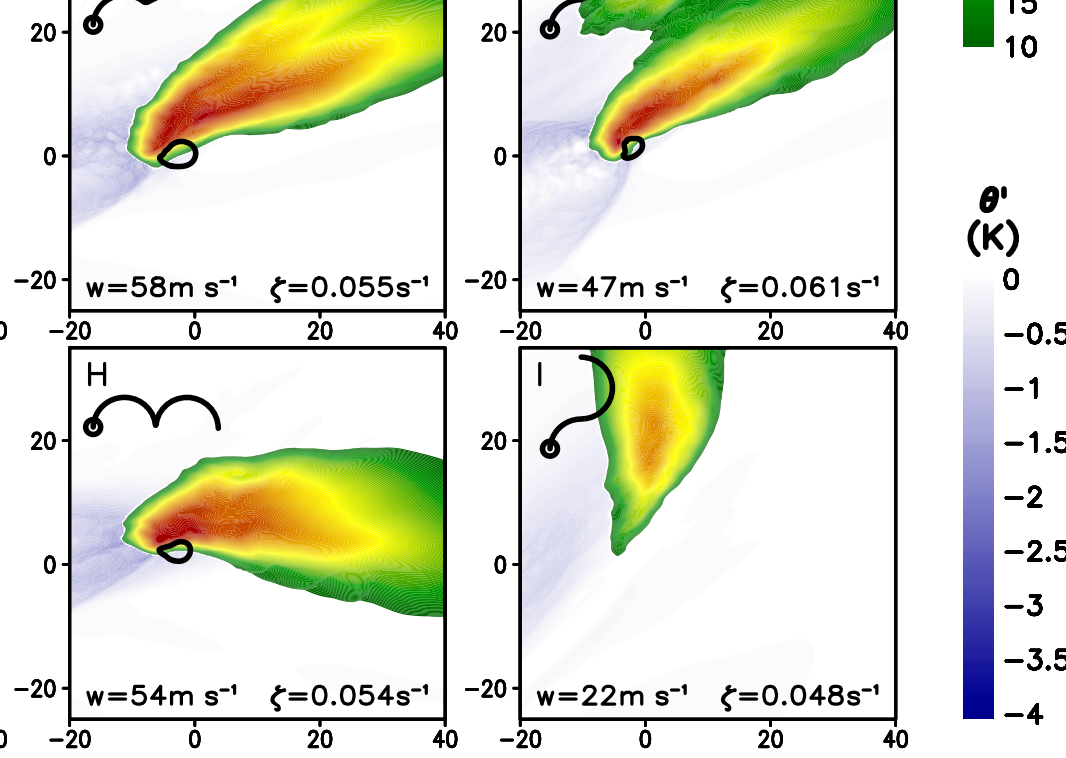

FIG. 3. Time-averaged surface radar reflectivity (dBZ; shaded green-red), surface potential temperature perturbation (K; shaded in blue, where not masked by reflectivity), and $3 \mathrm{~km}$ AGL vertical velocity (contoured in black at $10 \mathrm{~m} \mathrm{~s}^{-1}$ ) for $t=60-90 \mathrm{~min}$ for the nine primary sensitivity test simulations. For reference, the associated hodograph shapes are reproduced in the top left of each panel (and panels are in the same order as in Fig. 2). At the bottom of each panel, the 60-90-min-averaged maximum vertical velocity (at any height) and vertical vorticity (at $3 \mathrm{~km}$ AGL) are plotted; these two quantities are time averages of the minute-by-minute instantaneous maximum values. An animated version of this figure can be found in Fig. S2.

is worthwhile to ask in what ways the hodograph variations influence the vertical accelerations that ultimately sustain the storms. In this way, we can evaluate some of the working hypotheses laid out in section 1 . In the thermodynamic sounding used for these experiments [again, the composite near-inflow profile of VORTEX2 tornado cases from Parker (2014)], the height of the level of free convection (LFC) is just above $1.5 \mathrm{~km}$ AGL. Therefore, we first assess the total vertical accelerations at $1.5 \mathrm{~km}$ AGL (i.e., where lifting is necessary in order to sustain the influx of parcels into the convective updrafts); the accelerations at this altitude are also quite representative of averages taken over the $0.5-2.0 \mathrm{~km}$ AGL layer (not shown). The comparison is made in the same 60-90-min time period (Fig. 5), well after the initial warm bubble trigger, so that the local accelerations ultimately determine whether a mature supercell can be sustained. During this time frame, all of the simulations but I are rather steady (see animations in Fig. S2). Because simulation I is both unsteady and markedly different from the other eight simulations by this time period, it is discussed separately, in section $3 b$.

By the 60-90-min period, the simulations generally have maximum vertical velocities of roughly $50 \mathrm{~m} \mathrm{~s}^{-1}$ (except for I) and maximum 3-km vertical vorticities of roughly $0.05-0.07 \mathrm{~s}^{-1}$ (Fig. 5). In addition, all simulations (again, except for I) have rotation (red contours in Fig. 5) that is collocated with the main updraft (blue contours in Fig. 5). Within the eight healthy storms in Fig. 5, the $1.5 \mathrm{~km}$ AGL vertical accelerations are positive and substantial (generally $0.02-0.03 \mathrm{~m} \mathrm{~s}^{-2}$ ) within the footprint of the updraft, indicating strong lifting to 

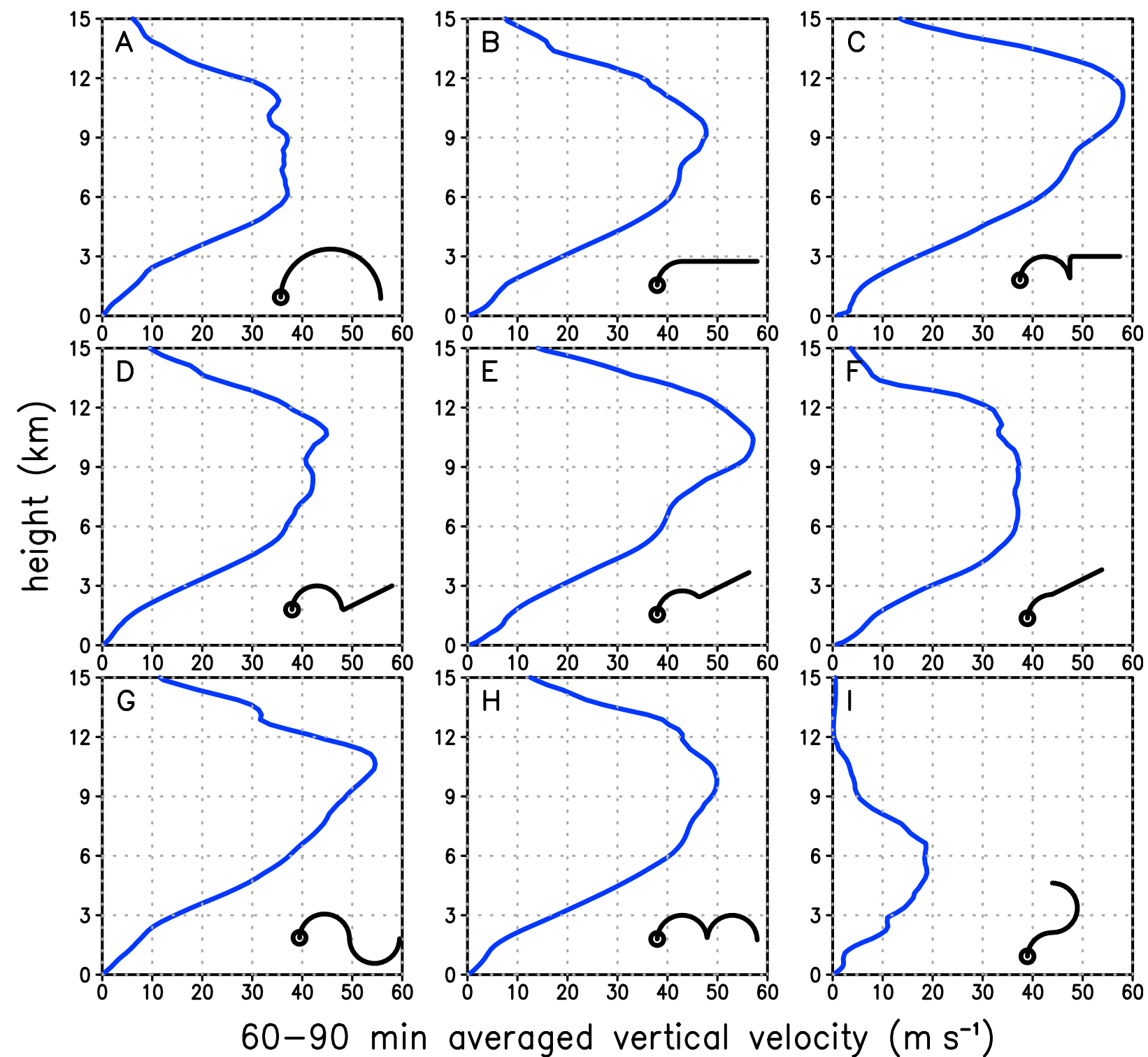

FIG. 4. Time-averaged vertical profiles of maximum vertical velocity $\left(\mathrm{m} \mathrm{s}^{-1}\right)$ for $t=60-90$ min for the nine primary sensitivity test simulations. For reference, the associated hodograph shapes are reproduced in the bottom right of each panel (and panels are in the same order as in Fig. 2). For each panel, the $y$ axis is height AGL ( $\mathrm{km})$. The plotted values are time averages of the instantaneous maximum values at each level; they are generally lower than the values reported at the bottom of the panels in Fig. 3, because those are averages of the instantaneous maximum at any level.

support sustenance of the maturing supercells. Again, as implied in Figs. 3 and 4, the half-circle hodograph produces vertical accelerations that are the weakest among the healthy simulations (profile A in Fig. 5). In other cases, the maximum in upward ACC is repositioned somewhat (relative to the updraft center) due to changes in the hodograph shape. Notwithstanding these subtle shifts, long-lived supercells result from the large upward accelerations that exist just beneath the main updraft's LFC in all but profile I. In the hodographs used here, the onset of backing with height is well above the height of the LFC; given the critical need for the lifting of air through the LFC, it is of interest to quantify the degree to which the hodograph farther aloft actually alters the dynamical components of acceleration at the level of the LFC (i.e., near $1.5 \mathrm{~km}$ ). For this more detailed comparison (Fig. 6), we focus on simulation A (which has the strongest veering profile) as well as simulations $\mathrm{G}$ and $\mathrm{H}$ (whose hodographs have the same starting and ending points as A but include a layer of backing aloft). 

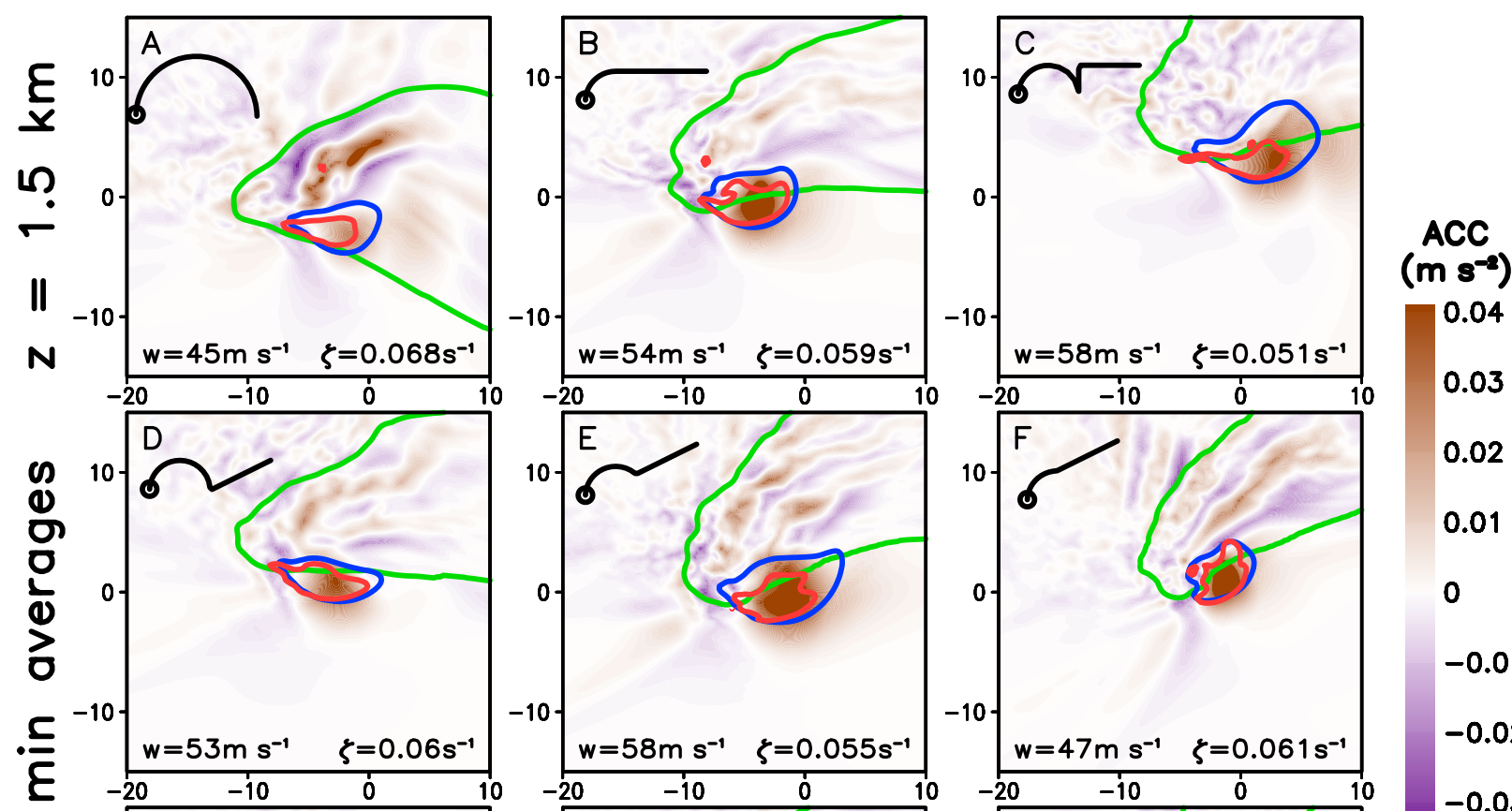

0.02

0.01

0

$-0.01$
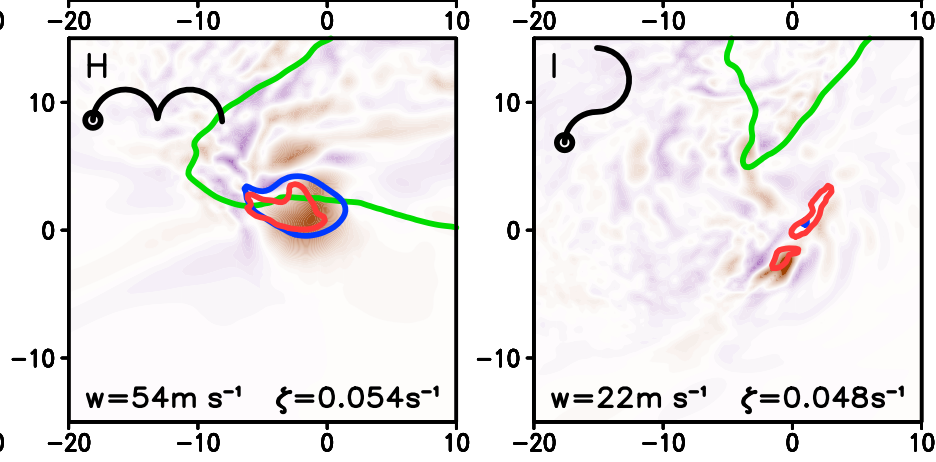

$-0.03$

$-0.04$

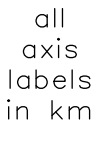

FIG. 5. Time-averaged vertical accelerations at $1.5 \mathrm{~km} \mathrm{AGL}\left(\mathrm{m} \mathrm{s}^{-2}\right.$; shaded), surface radar reflectivity (contoured in green at $20 \mathrm{~dB} Z$ ), averaged 1-5 km AGL vertical velocity (contoured in blue at $5 \mathrm{~m} \mathrm{~s}^{-1}$ ), and averaged 1-5 km AGL vertical vorticity (contoured in red at $0.005 \mathrm{~s}^{-1}$ ) for $t=60-90 \mathrm{~min}$ for the nine primary sensitivity test simulations. For reference, the associated hodograph shapes are reproduced in the top left of each panel (and panels are in the same order as in Fig. 2). At the bottom of each panel, the 60-90-min-averaged maximum vertical velocity (at any height) and vertical vorticity (at $3 \mathrm{~km}$ AGL) are reproduced from Fig. 3 .

Notably, ACCB is weakly positive in all three of these cases (Fig. 6, bottom row). This may seem surprising given that $1.5 \mathrm{~km}$ is just below the environment's LFC. The upward ACCB is attributable to the vertical perturbation pressure gradient acceleration; ACCB here can be most clearly understood in terms of "effective buoyancy," which is locally positive because latent heat release causes the core of the updraft to be less cold than its immediate surroundings (see Davies-Jones 2003). This ACCB ends up being slightly smaller in profiles $A$ and $G$, which have so much low-level veering that precipitation falls into the lowlevel inflow. With low-level storm-relative inflow from the east (i.e., $\mathrm{A}$ and $\mathrm{G}$ in Fig. 2), parcels experience some evaporative cooling on their way to the updraft. In terms of ACCB, then, decreased veering (the addition of backing) aloft may in fact be beneficial.
In terms of the other components of vertical acceleration at $1.5 \mathrm{~km}$ AGL, the three simulations are also quite similar. ACCDNL is weakly positive (smaller even than ACCB) within the footprint of the updraft in all three cases. For the hypothesis in section 1a, one would expect the largest impacts of backing aloft to be manifest in the updraft-shear interactions contained within ACCDL. As in earlier studies of this effect (e.g., Rotunno and Klemp 1982), the updraft-shear interactions produce couplets of upward and downward ACCDL that straddle the updrafts (Fig. 6, top row). For hodographs A, G, and $\mathrm{H}$, the general orientations of the couplets are similar owing to the rather similar 0-4-km hodograph shapes. The upward ACCDL is slightly stronger in the half-circle hodograph A (Fig. 6, top row) mainly because the $0-4-\mathrm{km}$ shear vector is larger than in the other two 

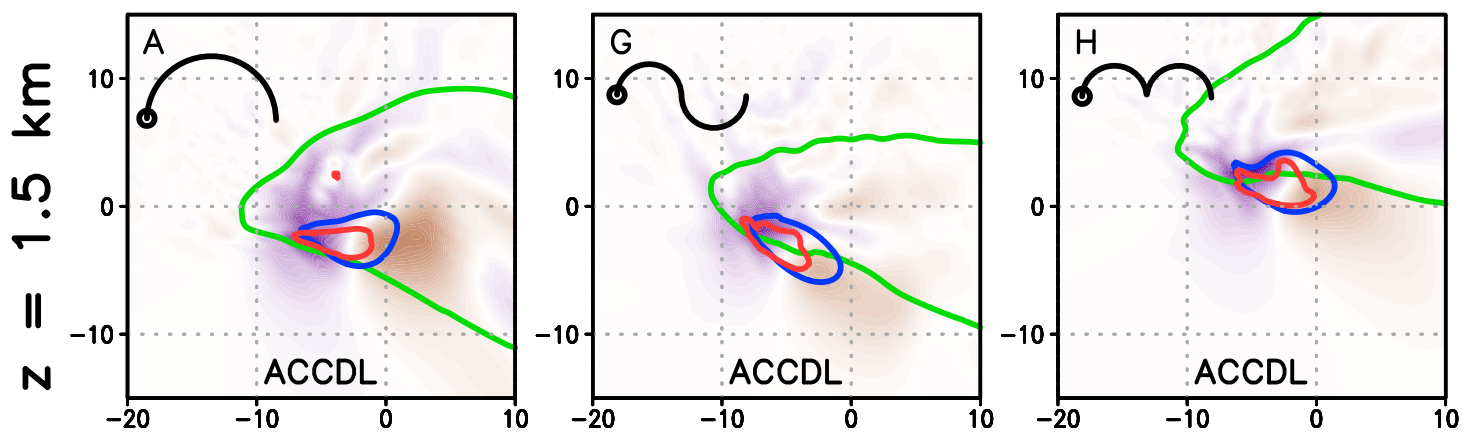

ACC

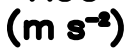

0.04

0.03
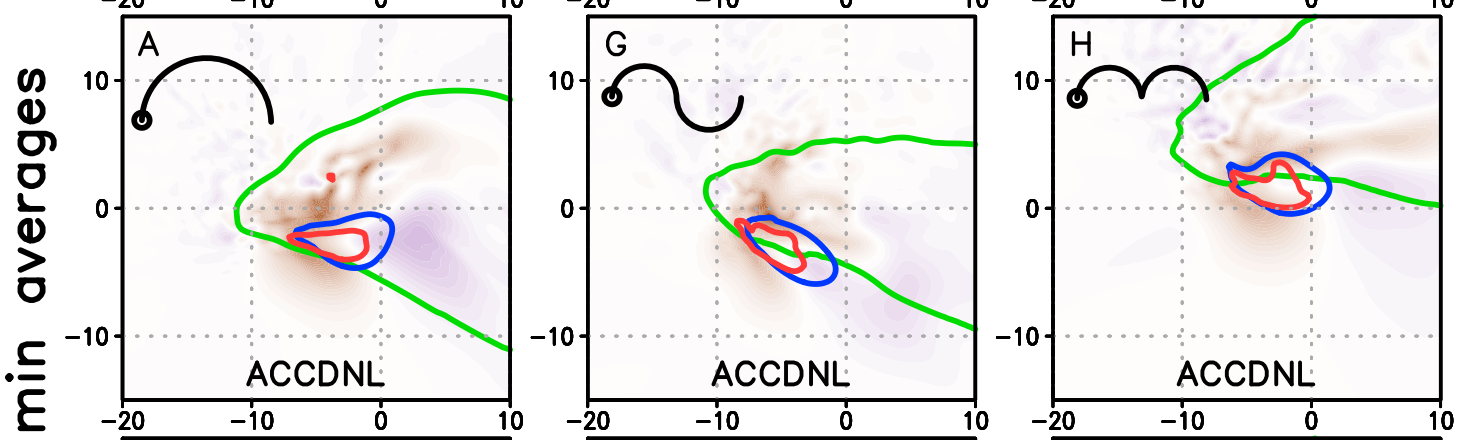

0.01

0

$-0.01$

$-0.02$
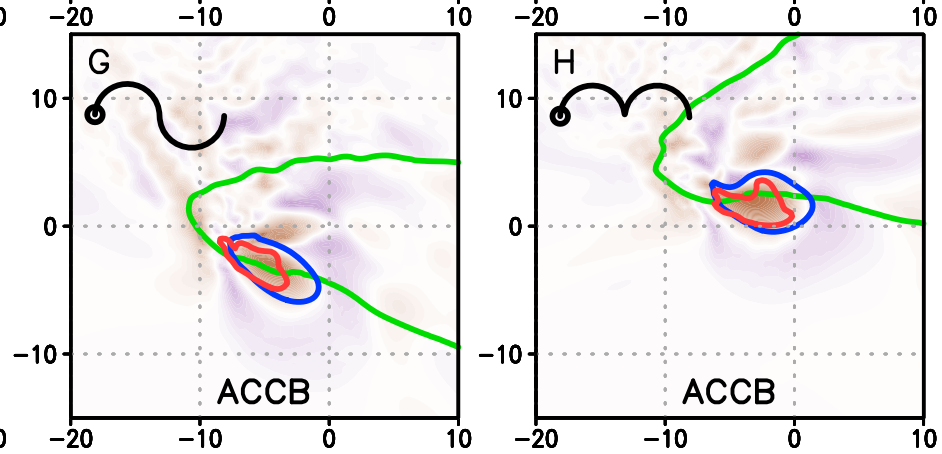

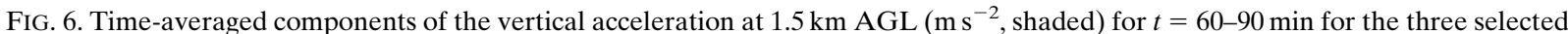
simulations. (top) ACCDL, as in (4); (middle) ACCDNL, as in (4); and (bottom) ACCB, as in (4). For reference, the associated hodograph shapes from Fig. 2 [(left) A, (center) G, and (right) H] are reproduced in the top left of each panel. Surface radar reflectivity (green), averaged 1-5 km AGL vertical velocity (blue), and averaged 1-5 km AGL vertical vorticity (red) are contoured as in Fig. 5.

simulations. But because the peak in the upward ACCDL values tends to occur on the flank of each updraft rather than centered within the updraft, the total ACC within the updraft of profile A does not exceed that in profiles $\mathrm{G}$ or $\mathrm{H}$.

Synthesizing the results shown in Figs. 5 and 6, it appears that near the height of the LFC $(\sim 1.5 \mathrm{~km} \mathrm{AGL})$, the vertical accelerations are not especially different among the eight healthy simulations. This results in the nearly identical averaged $3-\mathrm{km}$ vertical velocities shown in Fig. 4. A first-order explanation is that, because the LFC is well below the altitude at which backing with height occurs in the hodographs, the backing is simply too far aloft to directly impact the accelerations that maintain storms by lifting parcels upward through their LFCs. This would seem to invalidate the updraft-shear interaction hypothesis outlined in section $1 \mathrm{a}$.
Of course, this is not to say that the backing aloft has no discernible influence on the updrafts at all. Inspecting the accelerations at $4.5 \mathrm{~km}$ AGL, which falls within or adjacent to the layer of backing with height, reveals a much greater impact upon ACCDL (Fig. 7, top row). Within the envelope of the storms' updrafts, the $4.5-\mathrm{km}$ ACCDL is on average positive for the half-circle hodograph (profile A) and on average negative for the hodographs with backing (profiles $\mathrm{G}$ and $\mathrm{H}$ ). This is generally consistent with the updraft-shear interactions hypothesis from section 1a, but a few caveats apply. First, because these differences in ACCDL are well above the LFC, they may strengthen or weaken the midlevel updraft somewhat, but they are not determinative of whether or not the parcels continue to rise through the LFC and sustain the updraft (e.g., Fig. 4). Second, it is clear from Fig. 7 that both 

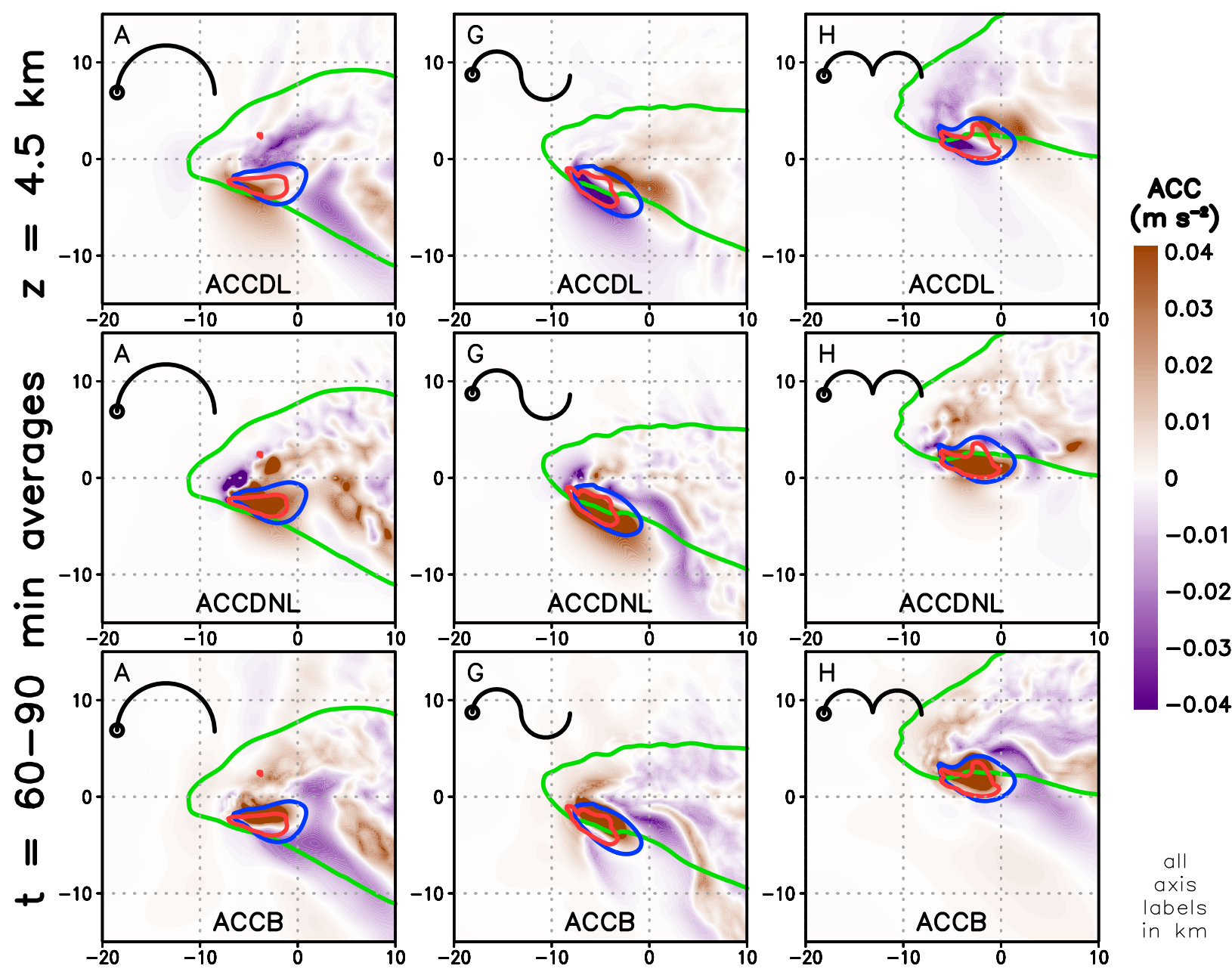

FIG. 7. As in Fig. 6, but at $4.5 \mathrm{~km}$ AGL.

ACCDNL and ACCB are positive and large throughout all three updrafts at the $4.5-\mathrm{km}$ level, meaning that these components more than compensate for any deficiencies in ACCDL (just as was shown by Weisman and Rotunno 2000). Indeed, despite its seemingly more favorable ACCDL field aloft in Fig. 7, it is clear from Figs. 3-5 than the half-circle simulation (profile A) ultimately produces updrafts that are not stronger than those in simulations $G$ and $H$. Taken altogether, the results presented here show that the dynamical updraft-shear impacts of backing aloft do have some effects on ACCDL, but these effects are also not determinative of convective maintenance or intensity.

\section{b. Failure mode in the disorganized supercell}

The discussion about impacts of backing aloft in the healthy supercell simulations cannot be completely generalized, because the storm in hodograph I remains weak and disorganized (I in Fig. 3-5). Animated output for simulation I (see Fig. S2) reveals an updraft that has vertical vorticity at times, but the storm appears to be continually interrupted, with new pulsing updrafts forming on its south-southeastern flank in a process reminiscent of back-building. These patterns of behavior in hodograph I are problematic enough that any study of the updraft accelerations must take place even earlier than in the other simulations $(t=20-50 \mathrm{~min}$; see Fig. 8), so that there is still a discernible updraft (blue contours in Fig. 8) with positive vertical vorticity (red contours in Fig. 8) in its immediate vicinity. Because of its substantial unsteadiness, the basic structure of this storm is difficult to infer from either a single altitude or from vertically averaged quantities; therefore, Fig. 8 instead depicts the updraft, vertical vorticity, and total vertical accelerations at six different height levels through the lower and middle troposphere.

In the midlevels (e.g., $3.5 \mathrm{~km}$ AGL at the bottom right in Fig. 8), the updraft generally surrounds the location $x=-4, y=2 \mathrm{~km}$. Although the components of acceleration are not shown here, the upward accelerations 


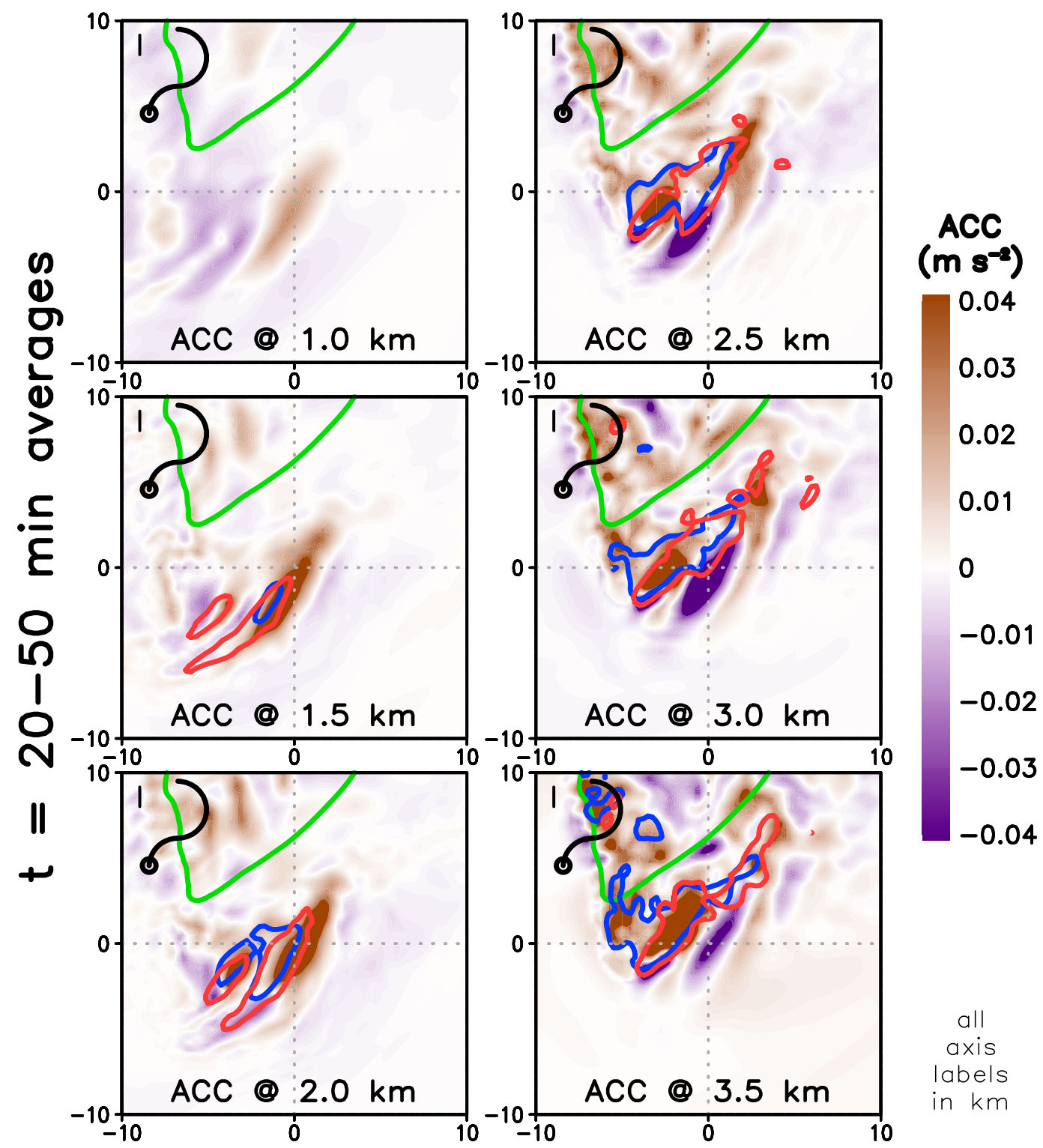

FIG. 8. Time-averaged vertical accelerations $\left(\mathrm{m} \mathrm{s}^{-2}\right.$, shaded), for heights ranging from 1.0 to $3.5 \mathrm{~km}$ AGL (labeled in each panel) for the run using hodograph I in Fig. 2, for $t=20-50 \mathrm{~min}$ (i.e., earlier, since convection becomes disorganized very quickly). Vertical velocity (contoured in blue at $5 \mathrm{~m} \mathrm{~s}^{-1}$ ) and vertical vorticity (contoured in red at $0.005 \mathrm{~s}^{-1}$ ) are shown for each specific altitude (this differs from the vertical averages shown in Fig. 5), along with surface radar reflectivity for reference (contoured in green at $20 \mathrm{dBZ}$ ). Note that the horizontal scale of this figure is smaller than in previous similar figures.

within this midlevel updraft are predominantly due to positive buoyancy (ACCB), as might be expected well above the height of the LFC. However, at lower altitudes, the vertical structures of the updraft, vertical vorticity, and acceleration fields become problematic. In the lowest $1-2 \mathrm{~km}$ (Fig. 8, left column) the vertical accelerations beneath the midlevel updraft $(x=-4, y=$ $2 \mathrm{~km}$ ) are weak or even negative. Instead, at 1.0, 1.5, and $2.0 \mathrm{~km}$ AGL, a zone of upward accelerations exists near the location $x=0, y=0 \mathrm{~km}$. This zone of upward forcing is predominantly due to ACCDNL (not shown) and corresponds to the position of the peak in vertical vorticity at $2.0 \mathrm{~km}$ (red contour in the bottom-left panel in Fig. 8). Above this altitude of peak vertical vorticity, ACCDNL (and thus total ACC) actually becomes downward near $x=0, y=0 \mathrm{~km}$ (e.g., in the 3.0- and 3.5$\mathrm{km}$ panels in Fig. 8). Taken altogether, the import of Fig. 8 is that there is no vertical column within which the 
total accelerations are persistently upward. The most straightforward explanation for this is that the low-level maximum in vertical vorticity (e.g., red contours at 1.5 and $2.0 \mathrm{~km}$ AGL in Fig. 8) occurs on the far southeastern edge of the midlevel updraft's position (e.g., blue contours at 3.0 and $3.5 \mathrm{~km}$ AGL in Fig. 8). In turn, this structure can be largely traced back to the environmental hodograph.

Environment I has sufficient deep-layer vertical shear for the production of supercells. The curious shape of the profile, however, produces a storm motion that falls very close to the hodograph (the storm motion is the origin in Fig. 2). As a consequence, the environment has the lowest SRH in this study (only $69 \mathrm{~m}^{2} \mathrm{~s}^{-2}$, computed using the actual simulated storm motion). This lack of SRH leads to very little correlation between the updraft and vertical vorticity (profile I in Figs. 5 and 8), as was originally explained by Davies-Jones (1984). Indeed, with the storm motion nearly overlaying hodograph I, the ambient horizontal vorticity is almost purely crosswise (profile I in Fig. 2). Coffer and Parker (2017) showed that this scenario tends to lead to very disorganized, transient low-level circulations.

Again, more widespread upward accelerations are found within the updraft of simulation I at higher altitudes (e.g., at $3.5 \mathrm{~km}$ AGL in Fig. 8). However, as noted for the simulations discussed in section $3 \mathrm{a}$, it is the accelerations near the height of the LFC $(\sim 1.5 \mathrm{~km}$ AGL) that are most determinative for storm maintenance; this appears to explain why simulation I is so unsteady, with continued development of new weak updrafts toward its south-southeastern flank. In this regard, the lack of ambient SRH, and subsequent inability of updraft rotation to contribute positive ACCDNL within the footprint of the midlevel updraft, appears to be critical. This finding seems to support the updraft rotation hypothesis outlined in section $1 \mathrm{~b}$, as hodograph $\mathrm{I}$ has the least SRH by far in the matrix of simulated environments (Fig. 2). Notably, among the other eight simulations, profile $\mathrm{F}$ has the second lowest SRH (Fig. 2), and it also produces a rather weak storm (F in Figs. 3-5).

Finally, it might be relevant that in hodograph I the layer of backing with height begins at a somewhat lower altitude (i.e., closer to the LFC) than in the other profiles used (Fig. 2). The possible ramifications of this are described with a supplemental set of experiments in the next subsection.

\section{c. Simulations with transition to backing at a lower altitude}

The hodographs used in this study were designed to produce very similar values of vertical wind shear in the 0-2-, 2-4-, and 4-6-km layers. As a consequence, the onset of backing with height in these profiles commences at varying heights, but generally close to $4 \mathrm{~km}$ AGL (e.g., profiles C, D, G, and H in Fig. 2). During discussion of Parker's (2016) earlier presentation of this work, Jared Guyer of the Storm Prediction Center (personal communication) indicated that backing in the layer 2$3 \mathrm{~km}$ AGL would be what typically catches a forecaster's attention. Although the controlled nature of the hodograph curvature and $0-6-\mathrm{km}$ bulk shear vector magnitude in Fig. 2 was highly desirable for this study, the assertion that backing aloft "matters more" when it occurs at lower altitudes is also a testable hypothesis. For this reason, four of the simulations with pronounced kinking or counterclockwise curvature were rerun with slightly modified hodographs, placing the transition to backing aloft at $2.5 \mathrm{~km}$ AGL (Fig. 9).

As documented in Fig. 10, these simulations produce steady supercells with impressive peak vertical velocities, all being within $4 \mathrm{~m} \mathrm{~s}^{-1}$ of the values in the original matrix of simulations (cf. Fig. 3). The reflectivity structures are comparable to those in the original set of simulations, and the footprint of strongest updraft (as indicated by the black contour) is broader in each of these four simulations than in their original counterparts (cf. profiles C, D, G, and H in Figs. 3 and 10). Overall, these four runs with a lower onset of backing (red data points in Fig. 11) produce higher averaged values of updraft helicity (UH; Kain et al. 2008) than any of the original nine simulations (black data points in Fig. 11). Perhaps this is not surprising given that these " $-2.5 \mathrm{~km}$ " hodographs generally have larger $0-3 \mathrm{~km} \mathrm{SRH}{ }^{4}$

Of course, there are a limitless number of other possible hodographs (in terms of shape, length, vertical distribution of veering versus backing, etc.). Nevertheless, the $-2.5-\mathrm{km}$ results help generalize the preceding findings, that is, that backing aloft (even when it occurs at a lower altitude) is not conclusively detrimental to storms on its own.

\section{Results from three-storm simulations}

As described in section $1 \mathrm{c}$, an alternative working hypothesis is that backing aloft may diminish chances for discrete supercells because it facilitates betweenstorm interactions (i.e., storm mergers or seeding of neighboring cells). We therefore build upon the

\footnotetext{
${ }^{4}$ In order to keep the hodograph shape and length fixed, but lower the height of the transition to backing, the $0-2.5-\mathrm{km}$ part of the hodograph became lengthened. Except for hodograph C, with its particular kink falling near $3 \mathrm{~km}$, this increased the $0-3-\mathrm{km}$ "clockwise area" circumscribed by each hodograph (which is proportional to SRH).
} 

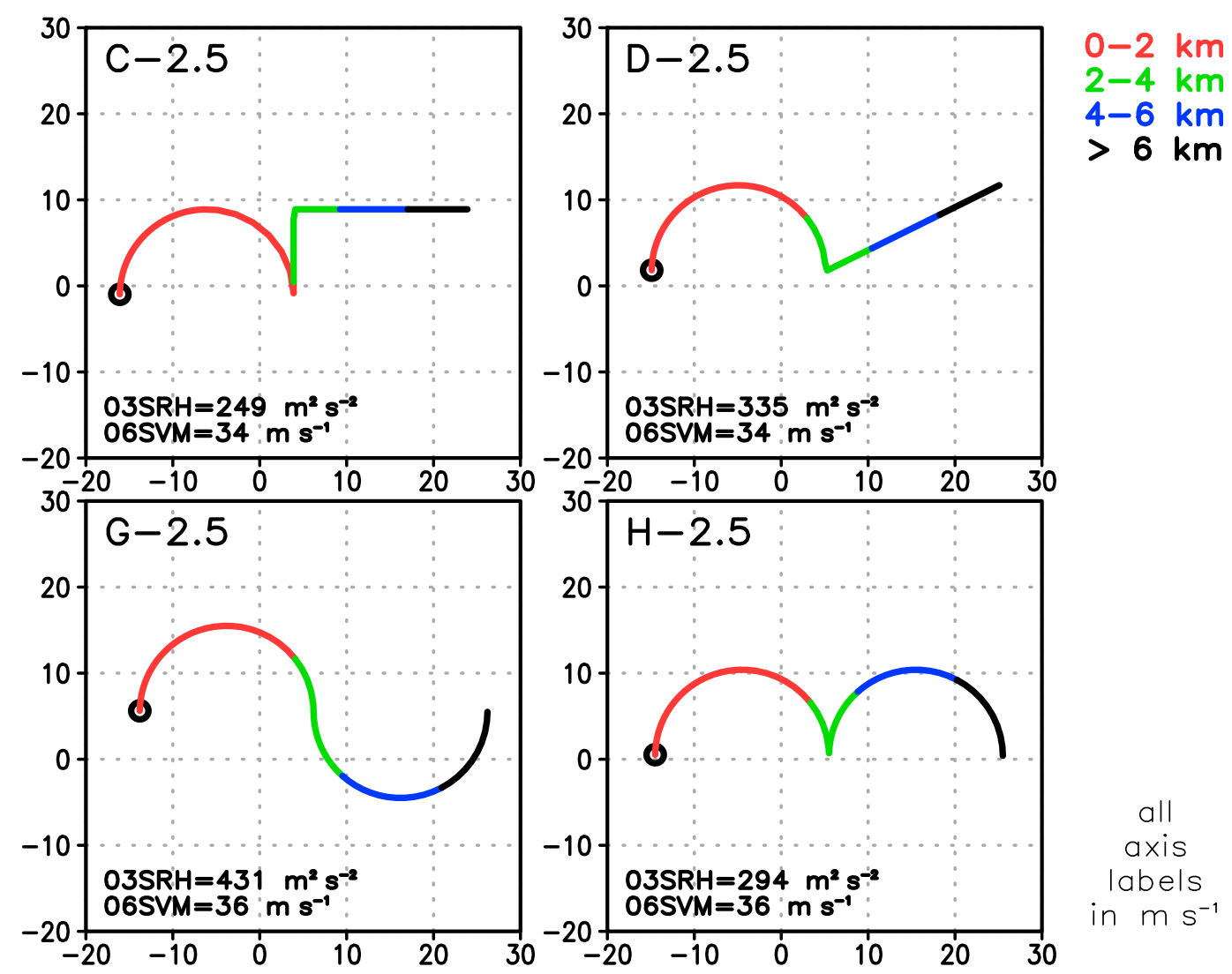

FIG. 9. As in Fig. 2, but for experiments in which the onset of backing in the profile occurs at a lower altitude (2.5 km AGL). These are directly comparable to profiles C, D, G, and H in Fig. 2.

single-storm experiments by initiating lines of three storms within the same set of environments. For brevity, we focus on simulations that included at least some backing aloft (i.e., mostly ignoring the classical halfcircle, A, and quarter-turn, B, hodographs). Hodograph I was also omitted, since it already failed to produce a well-organized single storm (section $3 b$ ). To separate the impacts of backing aloft (i.e., hodograph shape) from the impacts of along-line flow (i.e., hodograph orientation with respect to the line of storms), experiments are presented using both the original hodographs and hodographs that have been rotated $45^{\circ}$ to the left $(\mathrm{CCW})$ relative to the line of three initial warm bubbles. The early evolution of the individual cells within these runs was similar to what was shown in Figs. 3-7 (animations of reflectivity and updraft through $t=2 \mathrm{~h}$ are available in Fig. S3). To allow plenty of time for storm interactions, we focus our analysis later in the simulations (the $t=90$ 120 min window; Fig. 12).

\section{a. Original hodographs}

One of the most illuminating results from the three storm experiments is that the hodograph with the least backing aloft (profile F) produces by far the weakest convection (Fig. 12). This is a nearly straight hodograph with minimal SRH (only $112 \mathrm{~m}^{2} \mathrm{~s}^{-2}$, computed using the simulated storm motion). This finding reinforces the discussion of hodographs $\mathrm{F}$ and $\mathrm{I}$ in section 3, and further suggests that it is a deficiency in SRH, rather than the presence of backing aloft, that is of direct consequence in this parameter space. Hodograph $\mathrm{F}$ also has the largest averaged southerly component of wind in its vertical profile, which implies enhanced along-line flow. This attribute of hodograph $\mathrm{F}$ is also potentially impactful and is discussed further in the next subsection.

Beyond simulation $\mathrm{F}$, the other five simulations in the top two rows of Fig. 12 generally have at least one discrete supercell that persists into the 90-120-min window. In several of these cases, one or two of the remaining supercells are noticeably weaker than their neighbors (profiles D, G, and $\mathrm{H}$ in Fig. 12), likely because (by design) the storms were triggered in quite close proximity to one another. Even so, apart from profile F, the three-storm simulations (blue data points in Fig. 11) ultimately retain greater updraft helicity than their single-storm counterparts (black data points in Fig. 11). 


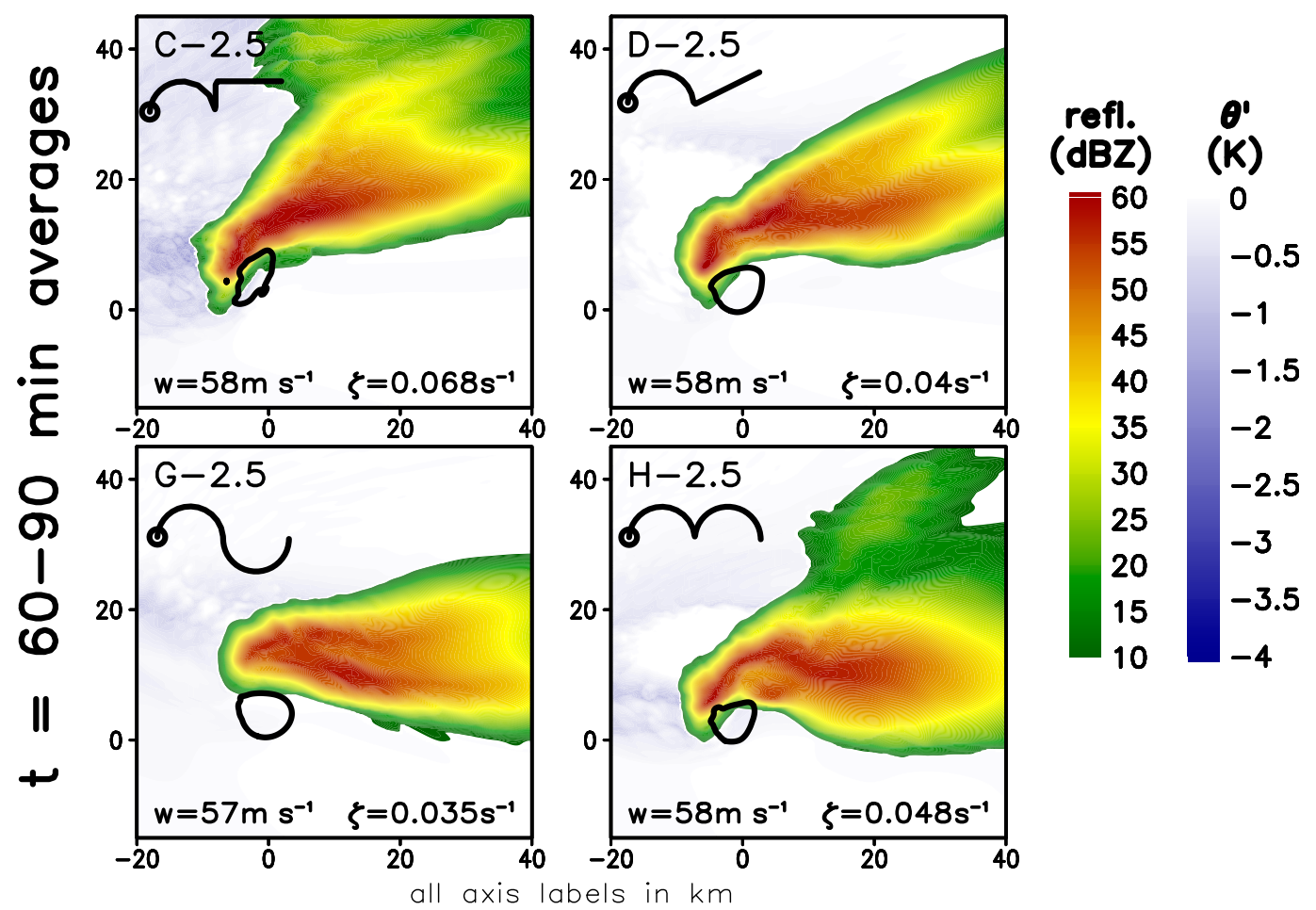

FIG. 10. As in Fig. 3, but for simulations using the "lower backing" hodographs shown in Fig. 9. For reference, the associated hodograph shapes are reproduced in the top left of each panel (and panels are in the same order as in Fig. 9).

Animations of the model output (Fig. S3) reveal that the destructive interactions between cells vary from run to run and are closely linked to small variations in the motions of the initial cells (leading alternatively to either interference or mergers with one another). Nevertheless, despite the presence of backing aloft, after $2 \mathrm{~h}$ strong rotating updrafts persist and discrete supercells remain the dominant mode in the simulations with the original hodograph orientations (profiles D, E, C, G, and $\mathrm{H}$ in Fig. 12). None of the simulations produces rapid upscale growth into a squall line.

Distilling these experiments, the presence of backing aloft, on its own, does not hinder the development and preservation of discrete supercells, even when storms are developing close to one another in a line. Therefore, we next consider whether it is instead the orientation of the upper-tropospheric flow (relative to the line of developing storms) that is determinative.

\section{b. Rotated hodographs}

As can be seen in the bottom row in Fig. 12, rotating the hodographs $45^{\circ} \mathrm{CCW}$ (relative to the initial line of storms) is one of the most impactful modifications among all of the present experiments. In terms of updraft helicity, the rotated three-storm simulations (green data points in Fig. 11) are generally weaker than their original three-storm counterparts (blue data points having the same SRH in Fig. 11). The backward-S hodograph (profile $G$ ), which produced a long-lived supercell in the single-storm simulation (Fig. 3), and at least one surviving supercell in the original three-storm experiment (profile $\mathrm{G}$ in Fig. 12), now produces much weaker convection by the end of the $2 \mathrm{~h}$ simulation (profile $\mathrm{G}^{*}$ in Fig. 12). The other two rotated profiles ( $\mathrm{C}^{*}$ and $\mathrm{H}^{*}$ in Fig. 12) still produce strong peak vertical velocities and vertical vorticity during the 90-120-min window, but it is clear that precipitation seeding of neighboring cells, as well as cell mergers and strengthening of the surface outflow, are beginning to commence. However, this fate does not require the presence of backing aloft ${ }^{5}$; the same general pattern of evolution

\footnotetext{
${ }^{5}$ As shown in Fig. S4, a line of three storms in the original quarter-circle hodograph (profile B) is long lived, whereas a threestorm simulation with a rotated version (profile $\mathrm{B}^{*}$ ) is similar to, but actually weaker than, what is shown for $\mathrm{H}^{*}$ in Fig. 12. Thanks to its large ambient SRH, the rotated half-circle hodograph $\left(\mathrm{A}^{*}\right)$ still supports three persistent discrete supercells, but forward-flank precipitation has nevertheless begun to contaminate the updrafts of neighboring storms by the $t=90-120 \mathrm{~min}$ window (Fig. S4).
} 


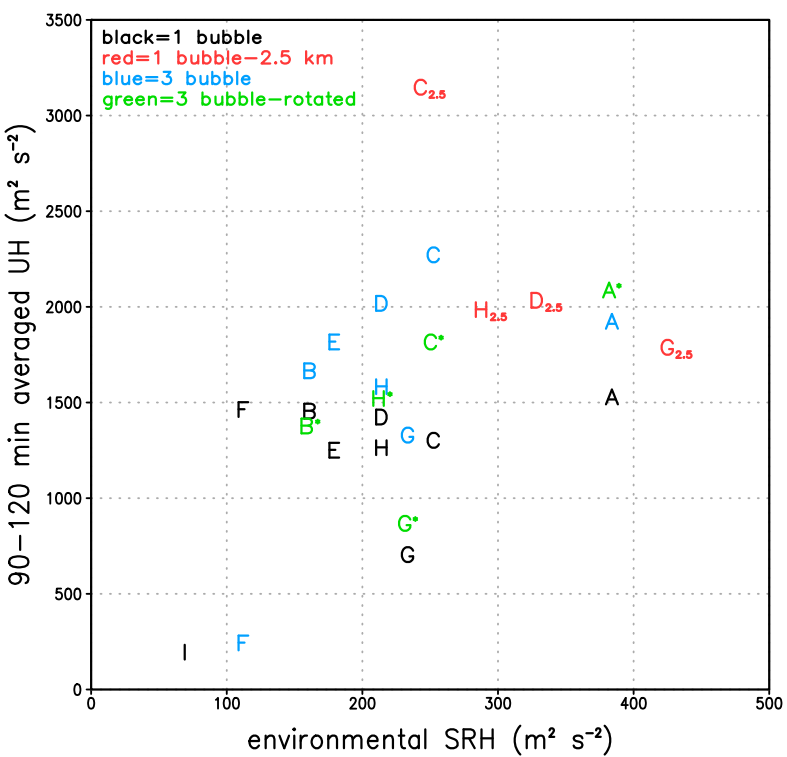

FIG. 11. Scatterplot of all simulations from this article, relating their 90-120-min-averaged 2-5 km AGL UH $\left[\mathrm{m}^{2} \mathrm{~s}^{-2}\right.$; Kain et al. (2008)] to their ambient environmental 0-3- $\mathrm{km} \mathrm{SRH}\left(\mathrm{m}^{2} \mathrm{~s}^{-2}\right)$. The $\mathrm{UH}$ values are time averages of the minute-by-minute instantaneous maximum values. The four general types of simulations are identified by different colors as shown in the legend. The letter for each data point indicates the corresponding hodograph shape in Fig. 3 (black points), Fig. 10 (red points), or Fig. 12 (blue and green points). Data points for the runs shown in Fig. S4 are also included (but not discussed).

is associated with the nearly straight hodograph $\mathrm{F}$ in Fig. 12, which also has substantial along-line flow.

The simulated impacts of along-line flow upon discrete cells largely conform to those reported in studies by French and Parker (2008) and Dial et al. (2010). But, the present suite of experiments reveals that backing aloft is neither necessary nor sufficient to produce these effects. The results from section 4 suggest that along-line flow in the upper troposphere is much more troublesome (with respect to long-lived discrete supercells) than is backing aloft, per se. The simulations in sections 3 and 4a make it clear that hodographs with backing aloft can definitely sustain discrete supercells.

\section{Longer-term impacts}

The preceding experiments reveal that there are few immediate impacts of backing aloft that uniformly hinder supercells. But, readers may reasonably wonder about possible longer-term impacts of backing aloft. Two hours should be sufficient to demonstrate the firstorder effects of backing aloft (as in hodograph I); put another way, a discrete supercell that survives for at least $2 \mathrm{~h}$ would not commonly be thought of as "struggling." But, it is possible that there are indirect effects of the wind profile that take quite some time to become apparent. Given limited computational resources, a subset of the simulations from sections 3 and 4 were restarted and run out through $t=3 \mathrm{~h}$. The particular choices for these extended runs (Table 1) were simulations that showed some signs of possible decline (in animations and time series of updraft metrics) at their original $t=2 \mathrm{~h}$ ending point. An animation of the $t=$ 2-3 h period is provided in Fig. S5 for 9 of these 10 cases (hodograph $\mathrm{F}$ is excluded because its low SRH has already been discussed earlier).

As reported in Table 1, each of the selected singlestorm simulations (A, F, G, and $\mathrm{H}$ ) experiences supercell dissipation prior to $t=3 \mathrm{~h}$. Hodograph $\mathrm{F}$ produced one of the least-steady storms among the original experiments, apparently due to its nearly straight structure with comparatively low SRH. As latent heating stabilized its environment, the storm's dynamical accelerations at some point were not sufficiently persistent to sustain it (not shown). In contrast, hodographs A, G, and $\mathrm{H}$ possess deep layers with $\mathrm{CW}$ curvature (e.g., Fig. 2), resulting in upper-level winds that are more veered than in the other experiments. This seems to be responsible for the primary problem the resulting supercells face: the continuing propensity for precipitation to fall into the storms' inflow sectors (e.g., Fig. 3; see also animations in the supplemental material). Over time, this noticeably reduces buoyancy within the storm updrafts (not shown, but described for earlier times in section 3a). It is possible that hodographs that become either straight or CCW curved at lower altitudes are actually preferable because they avoid this eventual failure mode (e.g., Fig. 10).

Among the three-storm simulations, at least one storm survives at $t=3 \mathrm{~h}$ in each case (Table 1 ). Whereas the $\mathrm{G}$ and $\mathrm{H}$ environments cannot sustain an isolated storm through $t=3 \mathrm{~h}$, surprisingly they do produce longer-lived discrete supercells when a group of three storms is initiated. Fluctuations in individual cells' motion vectors (likely due to outflow from neighboring cells; see supplemental animations) may help one or two supercells avoid the fate of excessive inflow sector precipitation described above (at least temporarily). The abrupt kink in hodograph $\mathrm{C}$ does not seem to be problematic on its own (Figs. 3-5 and 12, Table 1, etc.) but this profile produces upscale growth toward a linear structure when it is rotated to be more nearly along the line of cells (i.e., $C^{*}$ in Table 1 and animations in Figs. S3 and S5). This $C^{*}$ simulation is the clearest example of the development of a mesoscale cold pool over time, although even at $t=3 \mathrm{~h}$ the outflow is still not exceptionally cold. In contrast, for the other rotated profiles, the overall trend is toward dissipation of the storms: in 

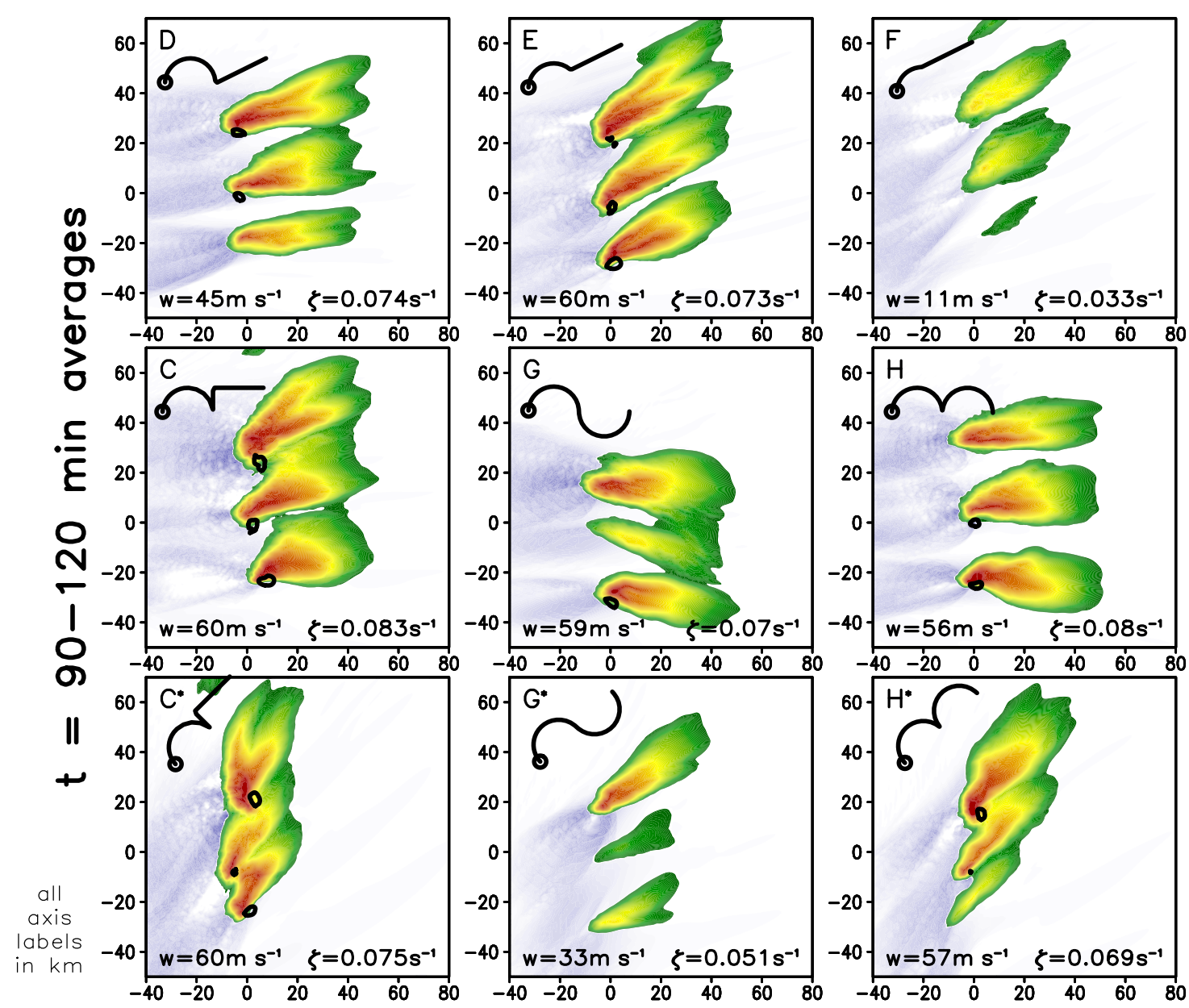

refl.

(dBZ)

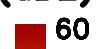

55

50

45

40

35

30

25

20
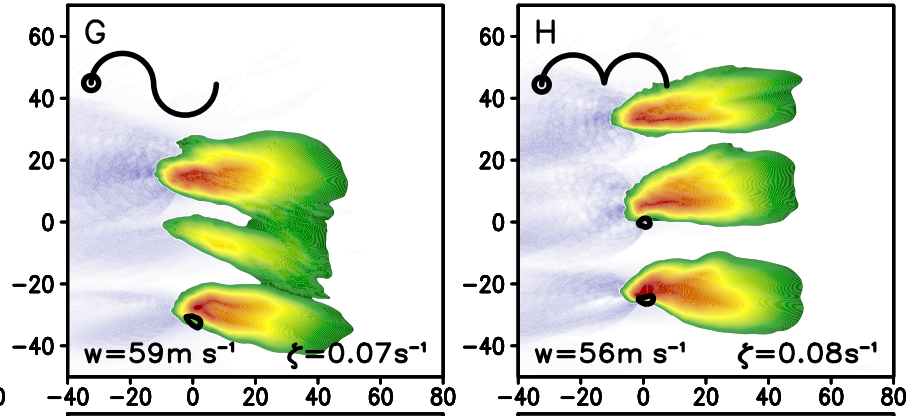

15

10
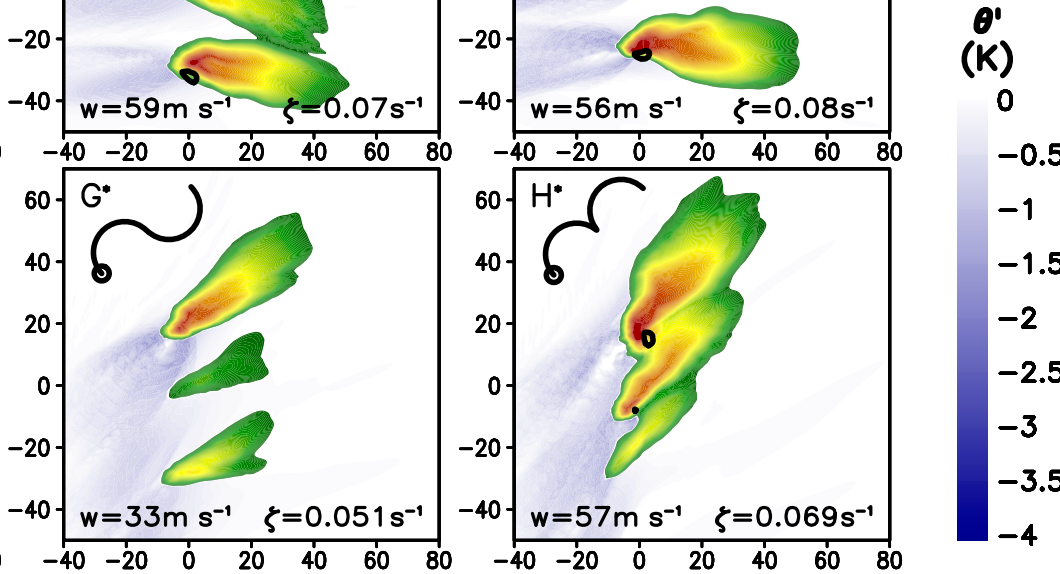

FIG. 12. As in Fig. 3, but for simulations using three initial warm bubbles, with averages performed for $t=90-120$ min (i.e., later, to allow storms more time to interact). For reference, the associated hodograph shapes are reproduced in the top left of each panel. The bottomrow hodographs are identical in shape to those in the middle row, but have been rotated $45^{\circ} \mathrm{CCW}$ relative to the line of warm bubbles. An animated version of this figure can be found in Fig. S3.

the $\mathrm{G}^{*}$ simulation dissipation had already occurred by $t=2 \mathrm{~h}$, and in both simulations $\mathrm{B}^{*}$ and $\mathrm{H}^{*}$ there are single storms left at $t=3 \mathrm{~h}$ with unmistakable downward trends (e.g., animations in Fig. S5).

Discussion of the varied details of these extended runs could probably constitute another article on its own; the stated goal of this study was simply to establish whether backing aloft causes an obvious direct hindrance to supercells. In summary, while the shorter-term direct impacts of backing aloft are generally small, the longerterm indirect impacts are less clear. Some of the singlestorm simulations with backing aloft eventually weaken at later times, but so do some of the simulations with little (hodograph F) or no (hodograph A) backing aloft. Even in the seemingly more unfavorable environments, when multiple storms are initiated, it seems that one or more may be fortunate enough to survive. In keeping with the discussion in sections 3 and 4, low environmental SRH and enhanced along-line flow seem to have the most straightforward, consistently deleterious impacts (with respect to long-lived discrete supercells).

\section{Conclusions}

This idealized modeling study was designed to isolate the impacts of backing aloft upon the within-storm processes associated with discrete supercell storm development. Revisiting the original working hypotheses, from section 1, we find the following.

- There is some evidence of the purported updraftshear interactions, which ultimately can lead to downward ACCDL when there is backing aloft. However, this tends to impact updraft air that is already well above the $L F C$, and it is therefore not determinative for supercell maintenance. Also, because of offsetting effects linked to ACCB and ACCDNL, 
TABLE 1. Summary of outcomes for simulations that were extended through $3 \mathrm{~h}$. Storm dissipation here is defined as the time at which the $3-\mathrm{km}$ vertical velocity falls below $10 \mathrm{~m} \mathrm{~s}^{-1}$ (and never recovers). Animations of the 2-3-h period are shown in Fig. S5 (for all runs in this table except for hodograph F).

\begin{tabular}{|c|c|c|}
\hline Trigger & Hodograph & Summary of behavior \\
\hline \multirow[t]{4}{*}{ One bubble } & A & Supercell dissipates at $2 \mathrm{~h} 20 \mathrm{~min}$ \\
\hline & $\mathrm{F}$ & Supercell dissipates at $2 \mathrm{~h} 35 \mathrm{~min}$ \\
\hline & $\mathrm{G}$ & Supercell dissipates at $2 \mathrm{~h} 20 \mathrm{~min}$ \\
\hline & $\mathrm{H}$ & Supercell dissipates at $2 \mathrm{~h} 25 \mathrm{~min}$ \\
\hline \multirow[t]{6}{*}{ Three bubble } & $\mathrm{C}$ & $\begin{array}{l}\text { Three supercells surviving at } 3 \mathrm{~h} \\
\qquad\left(w_{\max }=57 \mathrm{~m} \mathrm{~s}^{-1}\right)\end{array}$ \\
\hline & G & $\begin{array}{l}\text { One supercell surviving at } 3 \mathrm{~h} \\
\quad\left(w_{\max }=66 \mathrm{~m} \mathrm{~s}^{-1}\right)\end{array}$ \\
\hline & $\mathrm{H}$ & $\begin{array}{l}\text { Two supercells surviving at } 3 \mathrm{~h} \\
\quad\left(w_{\max }=42 \mathrm{~m} \mathrm{~s}^{-1}\right)\end{array}$ \\
\hline & B* & $\begin{array}{l}\text { One supercell surviving at } 3 \mathrm{~h} \\
\quad\left(w_{\max }=62 \mathrm{~m} \mathrm{~s}^{-1}\right)\end{array}$ \\
\hline & $C^{*}$ & $\begin{array}{l}\text { Emerging squall line by } 3 \mathrm{~h} \\
\qquad\left(w_{\max }=58 \mathrm{~m} \mathrm{~s}^{-1}\right)\end{array}$ \\
\hline & $\mathrm{H}^{*}$ & $\begin{array}{l}\text { One weak supercell surviving } \\
\text { at } 3 \mathrm{~h}\left(w_{\max }=22 \mathrm{~m} \mathrm{~s}^{-1}\right)\end{array}$ \\
\hline
\end{tabular}

supercells in profiles with backing aloft are not uniformly weaker than those in profiles without backing.

- There is more substantial evidence that profiles with large crosswise ambient vorticity and small ambient SRH produce weaker, more disorganized updraft rotation, and therefore smaller upward ACCDNL within the footprint of the updraft. These simulations reveal a weak-moderate relationship between SRH and updraft helicity (Fig. 11; correlation of $r=0.49$ ), as well as a possible lower threshold of SRH below which supercell organization becomes difficult even in large deep-layer vertical wind shear. This finding echoes the supercell climatologies of Rasmussen and Blanchard (1998) and Thompson et al. (2003). In at least one example (profile I), the lack of environmental SRH was attributable to backing aloft, which caused the storm motion vector to nearly overlay the environmental hodograph. But, this is not a problem common to all profiles with backing aloft (e.g., hodographs $\mathrm{C}, \mathrm{D}, \mathrm{E}, \mathrm{G}$, and $\mathrm{H}$ in this study), nor is it a problem that necessarily requires the existence of substantial backing aloft (e.g., hodograph $F$ in this study).

- There is no evidence that, on its own, backing aloft causes a line of developing supercells to necessarily dissipate or evolve into a linear convective mode due to accelerated storm interactions or mergers. Alongline flow has already been well established in the literature as promoting between-storm interactions. The present results uphold this, but such problematic along-line flow may occur with or without backing aloft. Hodograph shapes with backing aloft but without significant upper-tropospheric along-line flow do not seem to be an immediate hindrance to a line of developing supercells.

- While few short-term impacts on supercells can be specifically linked to backing aloft, the indirect impacts over many hours are less clear.

There were some symptoms that backing aloft influenced the distribution of hydrometeors within storms (e.g., the orientation of the forward-flank precipitation zones in Fig. 3). It is at least possible that too much $\mathrm{CW}$ curvature of the hodograph causes excessive precipitation to fall into a supercell's inflow sector, in which case at least modest backing aloft could be favorable for storm maintenance. But, a more robust test using other microphysical schemes should be attempted before presuming that this result is general.

The present idealized modeling approach was not suitable for identifying any impacts of backing aloft that might result from suboptimal synoptic-scale conditions. Perhaps backing aloft accompanies temperature fields or vertical motions that are atypical of supercell outbreaks. Given that such hodographs can still be associated with tornadoes and significant severe weather (Fig. 1 and counterexamples cited in section 1d), this hypothesis should probably also be met with skepticism. But, if there is some meteorological truth behind the anecdotal belief that backing aloft hinders the development of discrete supercells, then perhaps future work focused on such large-scale processes will uncover an explanation.

The present simulations, which focused on withinstorm and between-storm processes, show that backing aloft is not an unalloyed problem for the development of long-lived discrete supercells. The longevity of isolated supercells seems to be most directly hindered in environments with very low SRH or else (for a line of supercells) substantial along-line flow in the upper troposphere. Although these two properties can certainly accompany backing aloft, they are neither universally nor exclusively associated with it. In this respect, "backing aloft" appears to be a red herring. Viewed through the lens of storm dynamics, forecasters would likely be better served by directly assessing SRH and the orientation of the upper-level flow (presumably relative to the boundary expected to initiate storms) rather than becoming overly concerned with the presence of a CCW kink or curve in the environmental hodograph.

Acknowledgments. George Bryan is gratefully acknowledged for providing and supporting the CM1 model. Simulations were accomplished with highperformance computing support from Yellowstone 
(ark:/85065/d7wd3xhc) provided by NCAR's Computational and Information Systems Laboratory, sponsored by the National Science Foundation. This study was enhanced by beneficial comments from many people, especially Brett Borchardt, Brice Coffer, Johannes Dahl, Jared Guyer, Pat Hawbecker, Paul Markowski, Erik Rasmussen, Keith Sherburn, and Andy Wade. Three anonymous reviewers provided many thoughtful suggestions. This work was supported by the National Science Foundation under Grant AGS-1156123 and by the National Oceanic and Atmospheric Administration under Grants NA15OAR4590235 and NA16OAR4590213.

\section{REFERENCES}

Bluestein, H. B., and M. L. Weisman, 2000: The interaction of numerically simulated supercells initiated along lines. Mon. Wea. Rev., 128, 3128-3149, doi:10.1175/1520-0493(2000)128<3128: TIONSS $>2.0 . \mathrm{CO} ; 2$.

Brooks, H. E., C. A. Doswell III, and R. B. Wilhelmson, 1994: The role of midtropospheric winds in the evolution and maintenance of low-level mesocyclones. Mon. Wea. Rev., 122, 126-136, doi:10.1175/1520-0493(1994)122<0126:TROMWI>2.0.CO;2.

Browning, K. A., 1964: Airflow and precipitation trajectories within severe local storms which travel to the right of the winds. J. Atmos. Sci., 21, 634-639, doi:10.1175/1520-0469(1964)021<0634: AAPTWS $>2.0 . \mathrm{CO} ; 2$.

Bryan, G. H., and M. J. Fritsch, 2002: A benchmark simulation for moist nonhydrostatic numerical models. Mon. Wea. Rev., 130, 2917-2928, doi:10.1175/1520-0493(2002)130<2917: ABSFMN $>2.0 . \mathrm{CO} ; 2$.

- , and H. Morrison, 2012: Sensitivity of a simulated squall line to horizontal resolution and parameterization of microphysics. Mon. Wea. Rev., 140, 202-225, doi:10.1175/MWR-D-11-00046.1.

Coffer, B. E., and M. D. Parker, 2015: Impacts of increasing lowertropospheric vertical wind shear on supercells during the early evening transition. Mon. Wea. Rev., 143, 1945-1969, doi:10.1175/MWR-D-14-00328.1.

$\ldots$, and — 2017: Simulated supercells in nontornadic and tornadic VORTEX2 environments. Mon. Wea. Rev., 145, 149180, doi:10.1175/MWR-D-16-0226.1.

Davenport, C. E., and M. D. Parker, 2015: Impact of environmental heterogeneity on the dynamics of a dissipating supercell thunderstorm. Mon. Wea. Rev., 143, 4244-4277, doi:10.1175/ MWR-D-15-0072.1.

Davies-Jones, R., 1984: Streamwise vorticity: The origin of updraft rotation in supercell storms. J. Atmos. Sci., 41, 2991-3006, doi:10.1175/1520-0469(1984)041<2991:SVTOOU>2.0.CO;2.

_ 2003: An expression for effective buoyancy in surroundings with horizontal density gradients. J. Atmos. Sci., 60, 2922-2925, doi:10.1175/1520-0469(2003)060<2922:AEFEBI >2.0.CO;2.

Dawson, D. T., II, E. R. Mansell, and M. R. Kumjian, 2015: Does wind shear cause hydrometeor size sorting? J. Atmos. Sci., 72, 340-348, doi:10.1175/JAS-D-14-0084.1.

Deardorff, J. W., 1980: Stratocumulus-capped mixed layers derived from a three-dimensional model. Bound.-Layer Meteor., 18, 495-527, doi:10.1007/BF00119502.

Dial, G. L., J. P. Racy, and R. L. Thompson, 2010: Short-term convective mode evolution along synoptic boundaries. Wea. Forecasting, 25, 1430-1446, doi:10.1175/2010WAF2222315.1.
Doswell, C. A., III, and P. M. Markowski, 2004: Is buoyancy a relative quantity? Mon. Wea. Rev., 132, 853-863, doi:10.1175/ 1520-0493(2004)132<0853:IBARQ>2.0.CO;2.

French, A. J., and M. D. Parker, 2008: The initiation and evolution of multiple modes of convection within a meso-alpha-scale region. Wea. Forecasting, 23, 1221-1252, doi:10.1175/ 2008WAF2222136.1.

Jeevanjee, N., and D. M. Romps, 2015: Effective buoyancy, inertial pressure, and the mechanical generation of boundary layer mass flux by cold pools. J. Atmos. Sci., 72, 3199-3213, doi:10.1175/JAS-D-14-0349.1.

Kain, J. S., and Coauthors, 2008: Some practical considerations regarding horizontal resolution in the first generation of operational convection-allowing NWP. Wea. Forecasting, 23 , 931-952, doi:10.1175/WAF2007106.1.

Klemp, J. B., R. B. Wilhelmson, and P. S. Ray, 1981: Observed and numerically simulated structure of a mature supercell thunderstorm. J. Atmos. Sci., 38, 1558-1580, doi:10.1175/ 1520-0469(1981)038<1558:OANSSO > 2.0.CO;2.

Kumjian, M. R., and A. V. Ryzhkov, 2009: Storm-relative helicity revealed from polarimetric radar measurements. J. Atmos. Sci., 66, 667-685, doi:10.1175/2008JAS2815.1.

Lemon, L. R., and C. A. Doswell III, 1979: Severe thunderstorm evolution and mesocyclone structure as related to tornadogenesis. Mon. Wea. Rev., 107, 1184-1197, doi:10.1175/ 1520-0493(1979)107<1184:STEAMS>2.0.CO;2.

Mansell, E. R., C. L. Ziegler, and E. C. Bruning, 2010: Simulated electrification of a small thunderstorm with two-moment bulk microphysics. J. Atmos. Sci., 67, 171-194, doi:10.1175/ 2009JAS2965.1.

Markowski, P., and Y. Richardson, 2010: Mesoscale Meteorology in Midlatitudes. John Wiley and Sons, $430 \mathrm{pp}$.

— , and — 2014: The influence of environmental low-level shear and cold pools on tornadogenesis: Insights from idealized simulations. J. Atmos. Sci., 71, 243-275, doi:10.1175/ JAS-D-13-0159.1.

_- C. Hannon, J. Frame, E. Lancaster, A. Pietrycha, R. Edwards, and R. L. Thompson, 2003: Characteristics of vertical wind profiles near supercells obtained from the Rapid Update Cycle. Wea. Forecasting, 18, 1262-1272, doi:10.1175/ 1520-0434(2003)018<1262:COVWPN $>2.0$. CO;2.

Mulholland, J., J. W. Frame, and S. M. Steiger, 2015: A numerical investigation into the presence of veer-back-veer vertical wind profiles in supercell environments: A case study of 30 and 31 May 2013. 16th Conf. on Mesoscale Processes, Boston, MA, Amer. Meteor. Soc., 3.7, https://ams.confex.com/ams/16Meso/ webprogram/Paper274591.html.

Nowotarski, C. J., and A. A. Jensen, 2013: Classifying proximity soundings with self-organizing maps toward improving supercell and tornado forecasting. Wea. Forecasting, 28, 783801, doi:10.1175/WAF-D-12-00125.1.

Orf, L., R. Wilhelmson, B. Lee, C. Finley, and A. Houston, 2017: Evolution of a long-track violent tornado within a simulated supercell. Bull. Amer. Meteor. Soc., 98, 45-68, doi:10.1175/ BAMS-D-15-00073.1.

Parker, M. D., 2007a: Simulated convective lines with parallel stratiform precipitation. Part I: An archetype for convection in along-line shear. J. Atmos. Sci., 64, 267-288, doi:10.1175/ JAS3853.1.

_ 2007b: Simulated convective lines with parallel stratiform precipitation. Part II: Governing dynamics and associated sensitivities. J. Atmos. Sci., 64, 289-313, doi:10.1175/ JAS3854.1. 
_ 2010: Relationship between system slope and updraft intensity in squall lines. Mon. Wea. Rev., 138, 3572-3578, doi:10.1175/2010MWR3441.1.

- 2014: Composite VORTEX2 supercell environments from near-storm soundings. Mon. Wea. Rev., 142, 508-529, doi:10.1175/MWR-D-13-00167.1.

—- 2016: How much does backing aloft actually impact a supercell? 28th Conf. on Severe Local Storms, Portland, OR, Amer. Meteor. Soc., 6A.6, https://ams.confex.com/ams/ 28SLS/webprogram/Paper300986.html.

_ , and R. H. Johnson, 2004a: Simulated convective lines with leading precipitation. Part I: Governing dynamics. J. Atmos. Sci., 61, 1637-1655, doi:10.1175/1520-0469(2004)061<1637: SCLWLP $>2.0 . C O ; 2$.

$\longrightarrow$, and —, 2004b: Structures and dynamics of quasi-2D mesoscale convective systems. J. Atmos. Sci., 61, 545-567, doi:10.1175/1520-0469(2004)061<0545:SADOQM >2.0.CO;2.

Peters, J. M., 2016: The impact of effective buoyancy and dynamic pressure forcing on vertical velocities within two-dimensional updrafts. J. Atmos. Sci., 73, 4531-4551, doi:10.1175/JAS-D-16-0016.1.

Rasmussen, E. N., and D. O. Blanchard, 1998: A baseline climatology of sounding-derived supercell and tornado forecast parameters. Wea. Forecasting, 13, 1148-1164, doi:10.1175/ 1520-0434(1998)013<1148:ABCOSD > 2.0.CO;2.

— , and J. M. Straka, 1998: Variations in supercell morphology. Part I: Observations of the role of upper-level stormrelative flow. Mon. Wea. Rev., 126, 2406-2421, doi:10.1175/ 1520-0493(1998)126<2406:VISMPI >2.0.CO;2.

Rotunno, R., and J. B. Klemp, 1982: The influence of the shearinduced pressure gradient on thunderstorm motion. Mon.
Wea. Rev., 110, 136-151, doi:10.1175/1520-0493(1982)110<0136: TIOTSI $>2.0 . \mathrm{CO} ; 2$.

Thompson, R. L., R. Edwards, J. A. Hart, K. L. Elmore, and P. Markowski, 2003: Close proximity soundings with supercell environments obtained from the Rapid Update Cycle. Wea. Forecasting, 18, 1243-1261, doi:10.1175/1520-0434(2003)018<1243: CPSWSE $>2.0 . \mathrm{CO} ; 2$

, C. M. Mead, and R. Edwards, 2007: Effective storm-relative helicity and bulk shear in supercell thunderstorm environments. Wea. Forecasting, 22, 102-115, doi:10.1175/WAF969.1.

Warren, R. A., H. Richter, H. A. Ramsay, S. T. Siems, and M. J. Manton, 2017: Impact of variations in upper-level shear on simulated supercells. Mon. Wea. Rev., 145, 2659-2681, https:// doi.org/10.1175/MWR-D-16-0412.1.

Weisman, M. L., and R. Rotunno, 2000: The use of vertical wind shear versus helicity in interpreting supercell dynamics. J. Atmos. Sci., 57, 1452-1472, doi:10.1175/1520-0469(2000)057<1452: TUOVWS $>2.0 . \mathrm{CO} ; 2$.

Wicker, L. J., and R. B. Wilhelmson, 1995: Simulation and analysis of tornado development and decay within a threedimensional supercell thunderstorm. J. Atmos. Sci., 52, 2675-2703, doi:10.1175/1520-0469(1995)052<2675:SAAOTD>2.0.CO;2.

Wilhelmson, R. B., and Y. Ogura, 1972: The pressure perturbation and the numerical modeling of a cloud. J. Atmos. Sci., 29, 1295-1307, doi:10.1175/1520-0469(1972)029<1295: TPPATN $>2.0 . \mathrm{CO} ; 2$.

Ziegler, C. L., 1985: Retrieval of thermal and microphysical variables in observed convective storms. Part 1: Model development and preliminary testing. J. Atmos. Sci., 42, 1487-1509, doi:10.1175/ 1520-0469(1985)042<1487:ROTAMV>2.0.CO;2. 